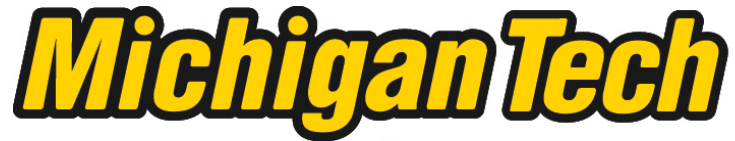 \\ Michigan Technological University Create the Future Digital Commons @ Michigan Tech
}

\section{COMPARISON OF NON-HEATING PALEOINTENSITY TECHNIQUES USING BASALTS FROM LEMPTÉGY VOLCANO, FRANCE AND SYNTHETIC MAGNETITE-BEARING SAMPLES}

Geoffrey A. Lerner

Michigan Technological University

Follow this and additional works at: https://digitalcommons.mtu.edu/etds

Part of the Geology Commons, and the Geophysics and Seismology Commons Copyright 2014 Geoffrey A. Lerner

Recommended Citation

Lerner, Geoffrey A., "COMPARISON OF NON-HEATING PALEOINTENSITY TECHNIQUES USING BASALTS FROM LEMPTÉGY VOLCANO, FRANCE AND SYNTHETIC MAGNETITE-BEARING SAMPLES", Master's Thesis, Michigan Technological University, 2014.

https://doi.org/10.37099/mtu.dc.etds/799

Follow this and additional works at: https://digitalcommons.mtu.edu/etds

Part of the Geology Commons, and the Geophysics and Seismology Commons 


\title{
COMPARISON OF NON-HEATING PALEOINTENSITY TECHNIQUES USING BASALTS FROM LEMPTÉGY VOLCANO, FRANCE AND SYNTHETIC MAGNETITE-BEARING SAMPLES
}

\author{
By \\ Geoffrey A. Lerner
}

\author{
A THESIS \\ Submitted in partial fulfillment of the requirements for the degree of \\ MASTER OF SCIENCE \\ In Geology \\ MICHIGAN TECHNOLOGICAL UNIVERSITY \\ 2014 \\ (C) 2014 Geoffrey A. Lerner
}


This thesis has been approved in partial fulfillment of the requirements for the Degree of MASTER OF SCIENCE in Geology.

Department of Geological and Mining Engineering and Sciences

Thesis Advisor: Aleksey V. Smirnov

Committee Member: $\quad$ Alessandro Tibaldi

Committee Member: $\quad$ Kari L. Anderson

Department Chair: John S. Gierke 
Peace on you too. 


\section{Table of Contents}

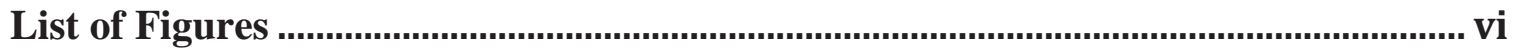

List of Tables.................................................................................................................ii

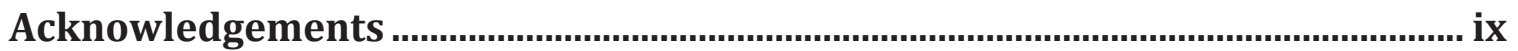

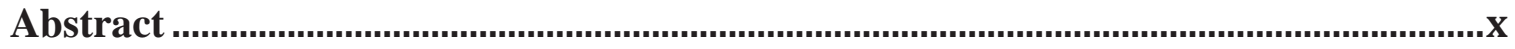

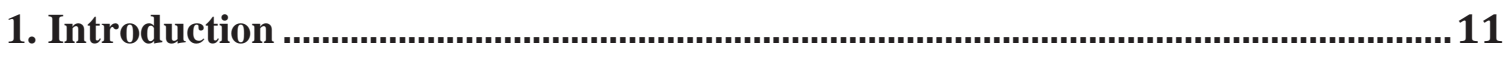

1.1. Introduction ................................................................................................................... 11

1.2. Goals of This Study ......................................................................................... 13

1.3. Review of Paleointensity Techniques ............................................................................... 13

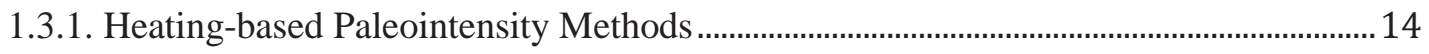

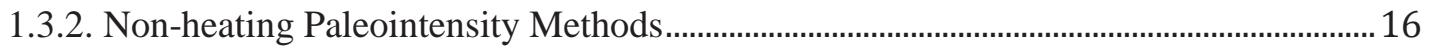

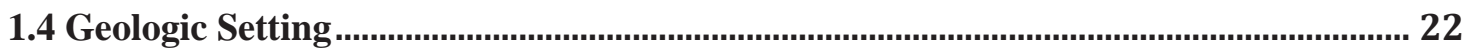

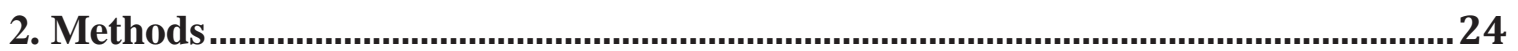

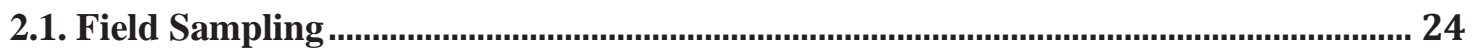

2.2. Sample Preparation..................................................................................................... 27

2.3. Rock Magnetism........................................................................................................ 28

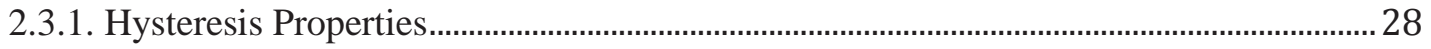

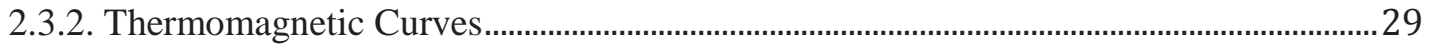

2.4. Paleomagnetic Analysis ................................................................................................ 30

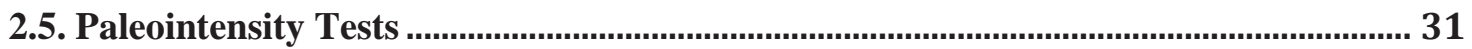

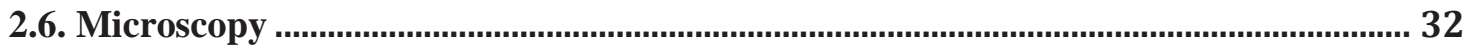

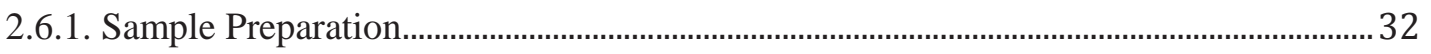

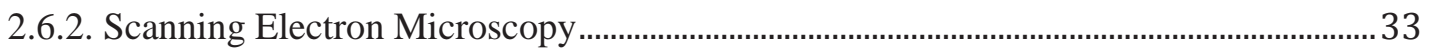

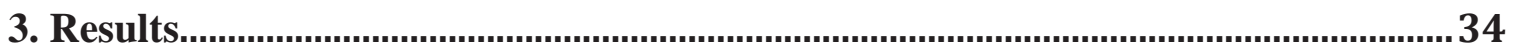

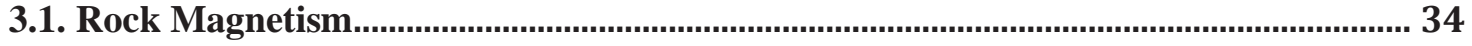

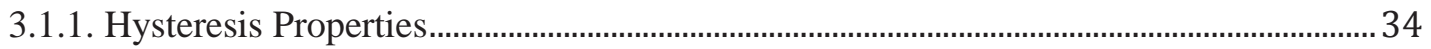

3.1.2. Temperature Dependence of Magnetic Susceptibility ………………………………..... 38

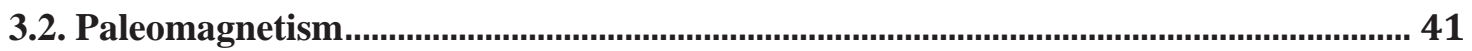

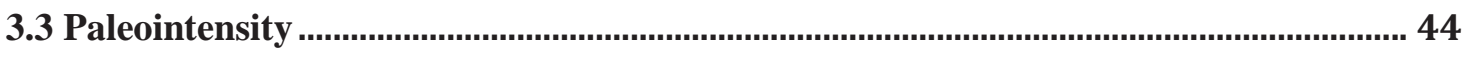




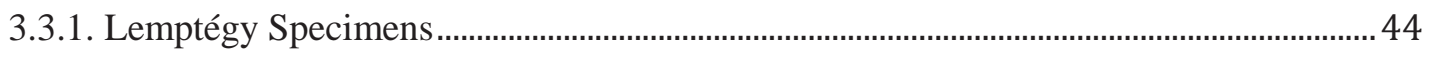

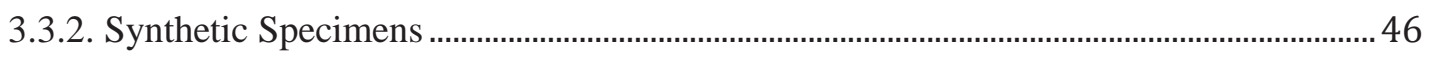

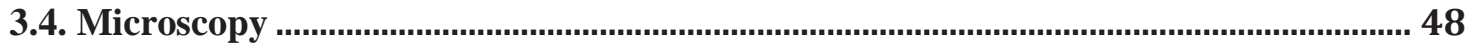

4. Discussion

4.1 Effectiveness of Non-Heating Paleointensity Methods................................................... 59

4.2 Relationship between Cooling Rate, Heating Alteration, and Magnetic Mineralogy

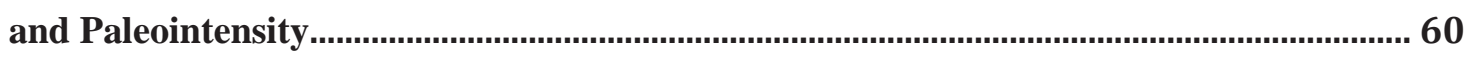

4.3 Cause of Heating Alteration in the Lemptégy Basalts ............................................. 61

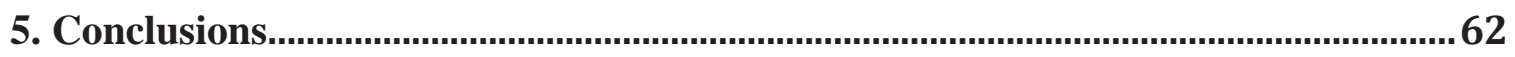

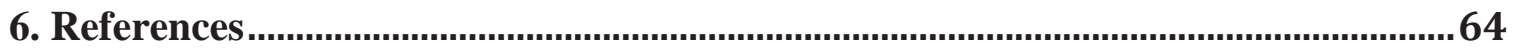




\section{List of Figures}

Figure 1.1: Arai plot for Pseudo-Thellier method analysis of a specimen comparing the loss of NRM versus the acquisition of ARM (both normalized).... 17

Figure 1.2: Arai plot for ARM method analysis of a specimen comparing the loss of NRM with the loss of ARM (both normalized) ..........................................................18

Figure 1.3: Example of a FORC diagram from a Lemptégy specimen ..........................20

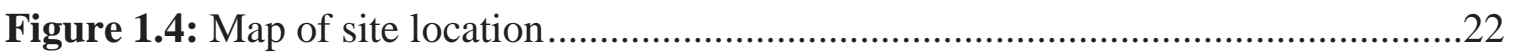

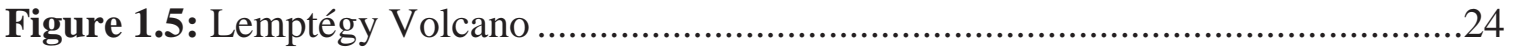

Figure 2.1: Map of Lemptégy Volcano with site locations marked ................................25

Figure 2.2: Drilling cores at Lemptégy Volcano ......................................................26

Figure 2.3: Cores drilled at Lemptégy site prior to orienting .....................................26

Figure 2.4: Cylindrical specimens cut from Lemptégy sample cores............................28

Figure 2.5: The magnetically shielded room in the Michigan Technological University

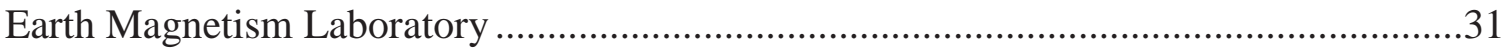

Figure 2.6: The FEI Philips XL 40 SEM located in Michigan Technological University's Minerals and Materials Engineering Building ........................................34

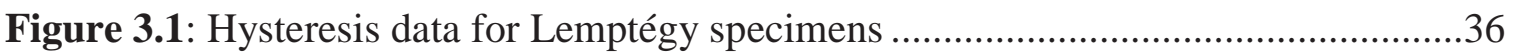

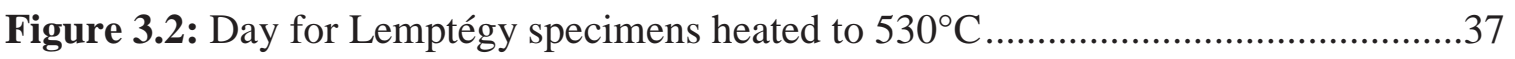

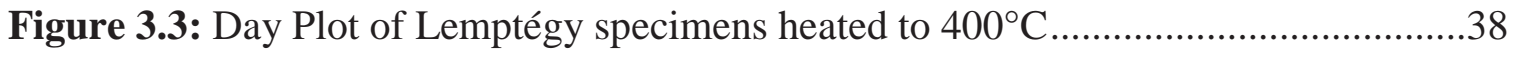

Figure 3.4: Typical thermomagnetic susceptibility curve for Lemptégy samples............39

Figure 3.5: Thermomagnetic curve of a Lemptégy specimen heated to $580^{\circ} \mathrm{C}$..............40

Figure 3.6: Thermomagnetic curve of a Lemptégy specimen heated to $400^{\circ} \mathrm{C}$..............40

Figure 3.7: Paleomagnetic plots for the thermal demagnetization of two representative

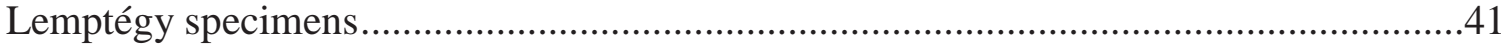

Figure 3.8: Paleomagnetic plots for the alternating field demagnetization of two

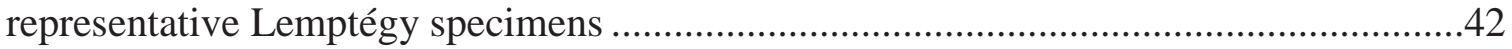

Figure 3.9: Equal area representation of LG sample paleodirections ............................43

Figure 3.10: Paleointensity estimates for the Lemptégy specimens ..............................46

Figure 3.11: Paleointensity estimates for the synthetic specimens ..............................48

Figure 3.12: A magnetite grain found in LG21E.................................................49

Figure 3.13: An image of the magnetite grain in Figure 3.12 taken at $1200 x \ldots \ldots \ldots \ldots . . . .50$

Figure 3.14: An EDS spectrum from the light phase of the specimen in Figure 3.12 .....50

Figure 3.15: An EDS spectrum from the dark phase of the specimen in Figure 3.12 2.....50 
Figure 3.16: Exsolution lamellae in a magnetite grain in LG21W at 1000x

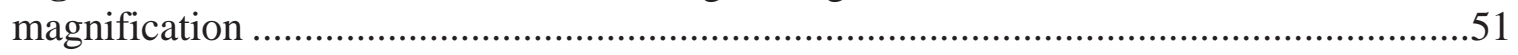

Figure 3.17: Magnetite grain from LG21W shown at 350x ....................................52

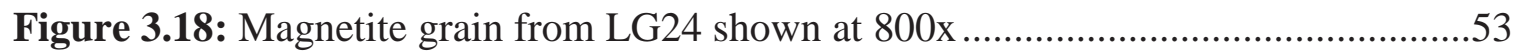

Figure 3.19: Magnetite grain from LG24 shown at 800x .......................................53

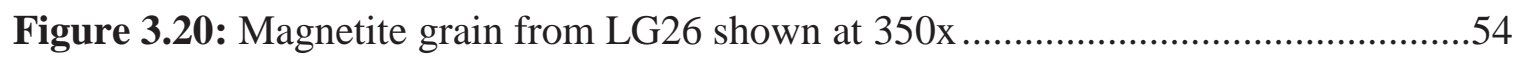

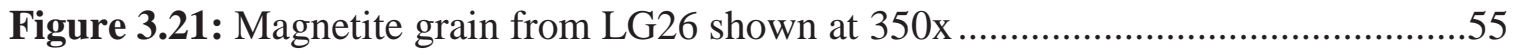

Figure 3.22: Comparison of the abundance of magnetic grains in the dike specimens

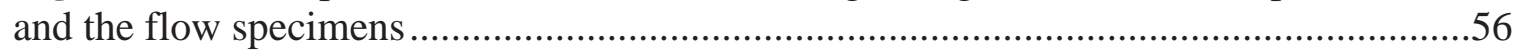

Figure 3.23: Comparison of an LG21E magnetite grain before and after heating to $600^{\circ} \mathrm{C}$

Figure 3.24: Comparison of an LG26 magnetite grain before and after heating to $600^{\circ} \mathrm{C}$ 


\section{List of Tables}

Table 1.1: Summary of main features of modern paleointensity methods .....................21

Table 3.1: Summary of paleomagnetic data from Lemptégy samples ...........................42

Table 3.2: Summary of paleointensity data from Lemptégy samples............................44

Table 3.3: Summary of paleointensity data from synthetic samples .............................47 


\section{Acknowledgements}

I would like to thank my adviser Aleksey Smirnov for offering me a great project to work on and for being so patient and flexible when things didn't work out quite like we had planned, and for teaching me so much in such a short time, Alessandro Tibaldi for helping me navigate the Italian portion of my INVOGE degree, Benjamin van Wyk de Vries for providing me with an amazing site to do my field work, Michael Petronis and Adam Brister for collecting the samples with me at Lemptégy

Thanks to the entire MTU Pmag group, without whose guidance and inclusiveness I could never have made it this far: Kari Anderson for for teaching me lots about Pmag when I knew nothing, Evgeniy Kulakov for providing the synthetic samples, Marine Foucher for answering my endless supply of Pmag questions, and a special thanks to Elisa Piispa for the countless hours spent teaching me to use equipment, sending me articles, discussing paleointensity methods, and just generally giving me good advice when I needed it.

Lastly, thank you to all my friends and classmates in Milan, Houghton, and Clermont-Ferrand for making the last two years so exciting, interesting, and enjoyable every step of the way. 


\begin{abstract}
$\underline{\text { Abstract }}$
Data of the strength of Earth's magnetic field (paleointensity) in the geological past are crucial for understanding the geodynamo. Conventional paleointensity determination methods require heating a sample to a high temperature in one or more steps. Consequently, many rocks are unsuitable for these methods due to a heatinginduced experimental alteration. Alternative non-heating paleointensity methods are investigated to assess their effectiveness and reliability using both natural samples from Lemptégy Volcano, France, and synthetic samples. Paleointensity was measured from the natural and synthetic samples using the Pseudo-Thellier, ARM, REM, REMc, REM', and Preisach methods.

For the natural samples, only the Pseudo-Thellier method was able to produce a reasonable paleointensity estimate consistent with previous paleointensity data. The synthetic samples yielded more successful estimates using all the methods, with the Pseudo-Thellier and ARM methods producing the most accurate results. The PseudoThellier method appears to be the best alternative to the heating-based paleointensity methods.
\end{abstract}




\section{Introduction}

\subsection{Introduction}

The study of paleointensity, the strength of Earth's magnetic field at a given point in the past, has become an important field for learning about the history of the Earth and its development. Since the development of the first paleointensity methods in the middle of the $20^{\text {th }}$ century, the investigation of paleointensity has been an important tool for studying the geodynamo. As paleomagnetists have obtained more detailed paleointensity data, it has allowed for the creation of more detailed hypotheses about the history of the geodynamo and the formation of the Earth's inner core (Tarduno et al., 2006). However, the ability of scientists to study paleointensity has always been limited by the types of rocks that are viable for paleointensity experiments.

The original method for determining paleointensity was developed by Émile and Odette Thellier in 1930s and 1940s. A key component of this method (the ThellierThellier method) is the stepwise heating of the specimens to replace the original thermal remanent magnetization (TRM), the remanence (magnetic intensity and direction) a rock naturally acquires when cooling from a high temperature, with an artificial laboratory remanence of known intensity. The Thellier-Thellier method (and other techniques that use heating steps) relies on the comparison of a specimen's natural TRM with that acquired in the laboratory (Dunlop, 2011). To this day, the Thellier-Thellier method is generally the most trusted and relied-upon method for paleointensity. Other more recently developed methods, such as the multi-specimen method (Dekkers and Böhnel, 2006; Hoffman et al., 1989) and the Shaw method (Shaw, 1974; Yamamoto et al., 2003) have sought to reduce the number of heating steps involved in paleointensity studies in an effort to minimize laboratory-induced high-temperature alteration. Nevertheless, most of the trusted paleointensity methods that have been developed involve at least one heating step to a high temperature.

The necessity for a heating step in the paleointensity procedure severely limits the types of specimens that can be used in these experiments. Sediments and sedimentary rocks do not acquire a remanence through cooling, and thus cannot be analyzed with heating-based methods (Dunlop and Özdemir, 1997). Even many intrusive and extrusive 
rocks whose remanence is of thermal origin undergo some form of chemical alteration when heated to a high temperature. Any measurements taken of the rock after a hightemperature heating step would result in measurements of a specimen with different properties than at the start of the experiment, rendering any results unreliable. As a result, any rock that undergoes any kind of thermal alteration would be considered unsuitable for most paleointensity experiments.

More recently, methods of testing for paleointensity that do not involve any heating steps have been developed to avoid the problem of experimental alteration. These methods make use of magnetic properties of rocks not usually considered in heatingbased methods to eliminate the heating steps of the paleointensity procedure.

These properties include anhysteretic remanent magnetization (ARM), an artificial remanence created in the lab by superimposing an alternating magnetic field on a small direct field (Butler, 1992). This can be compared with the rock's original NRM (natural remanent magnetization; the full remanence a rock carries at the time it is sampled) or TRM. One method of comparison is used in the ARM method (Markert and Heller, 1972), which compares the decay of original TRM with the decay of lab-created ARM. Another approach is used in the Pseudo-Thellier method (Tauxe et al., 1995), in which the rate of decay of TRM is compared with the rate of acquisition of ARM.

Saturation isothermal remanent magnetization (SIRM), the remanence created in a rock after it has been magnetized by a saturating magnetic field at room temperature, is used in the trio of REM (ratio of equivalent magnetizations) methods (Acton et al., 2007; Gattacceca and Rochette, 2004) in which the SIRM at different points in its demagnetization spectrum is compared to the decay of NRM.

FORC (first order reversal curve) diagrams, a measurement of a rock's hysteresis properties over a range of applied magnetic fields that provides more detailed rock magnetic information than a magnetic hysteresis loop (Mayergoyz, 1986; Pike et al., 1999), are used in the most recently developed method, which uses a numerical Preisach model (Muxworthy and Heslop, 2011; Muxworthy et al., 2011) to simulate TRM acquisition and determine paleointensity. 
There is little agreement in the paleomagnetism community about which of these nonheating methods are most effective. Some have concluded that ARM is a better analogue of TRM than SIRM (Lappe et al., 2013), while others have come to the opposite conclusion (Yu, 2006). It has also been determined that methods involving these properties can be grain-size dependent (Yu, 2006, 2010). Additionally, some of these methods do not directly provide a paleointensity estimate, but rather a value that must be multiplied by a correction factor in order to reach an estimate. The correction factor used by different authors in order to get a correct result varies widely (Acton et al., 2007; Gattacceca and Rochette, 2004; Lappe et al., 2013; Yu, 2006) which raises questions about how universally these methods can be applied.

\subsection{Goals of This Study}

This study seeks to compare the various non-heating paleointensity methods in order to determine which are the most accurate and reliable. In order to do this, the different methods (ARM, REM, REMc, REM', Pseudo-Thellier, and Preisach) will be carried out on both synthetic magnetite samples of varying grain size as well as natural samples from Lemptégy volcano in France. Additionally, the magnetic mineralogy of the Lemptégy samples will be examined using scanning electron microscopy before and after heating to better understand the cause of the heating alteration that is the motivator for non-heating paleointensity methods.

\subsection{Review of Paleointensity Techniques}

In order to understand the flaws inherent in heating-based paleointensity techniques and the attempts of non-heating techniques to improve upon them, it is necessary to understand the methodology of these approaches. What follows is a review of the main heating-based paleointensity methods and the non-heating methods that will be used in this study. 


\subsubsection{Heating-based Paleointensity Methods}

\section{A. Thellier-Thellier method}

The original paleointensity method (Thellier and Thellier, 1959) is based on the comparison of the decay of TRM during thermal demagnetization with the acquisition of a laboratory TRM during a series of heating and cooling steps in a known artificial field.

A specimen is first subjected to thermal demagnetization, by repeatedly heating the specimen to increasingly higher temperatures, then allowing it to cool. This removes the specimen's original TRM and provides a demagnetization curve. The specimen is then imparted with artificial TRM (called pTRM) in a stepwise manner by again heating (and then cooling) to increasing temperatures, this time in a known artificial field. Most versions of the Thellier method also use pTRM checks, a step in which earlier steps are repeated to ensure the reliability of the results (Coe and Gromme, 1973; Dunlop, 2011).

The plot of NRM remaining versus pTRM gained can be used to determine a paleointensity estimate by multiplying the slope of the line by the known laboratory field. This plot, called an Arai plot, is used as the basis for evaluating paleointensity data in most of the subsequently developed methods by plotting comparison of the loss or gain of the relevant types of remanence.

While a number of alterations to these methods have been attempted over the years, including low temperature demagnetization (LTD; a method in which specimens are bathed in liquid nitrogen in the hopes of removing unwanted portions of their remanence) (Yamamoto et al., 2003), the stepwise heating has remained the primary component of the method.

\section{B. Multi-specimen method}

The multispecimen method was developed by Hoffman et al. (1989) as an alternative to the Thellier-Thellier method in an attempt to reduce the number of heating steps used. In this approach, each multiple specimens (or subspecimens) from the same site are used in order to provide more material. The original protocol calls for the heating of each specimen five times $\left(M_{1}-M_{5}\right)$. The first three heatings $\left(M_{1}-M_{3}\right)$ are done at increasing temperatures $\left(\mathrm{T}_{0}, \mathrm{~T}_{1}, \mathrm{~T}_{2}\right)$ and cooled in a zero field, with $\mathrm{M}_{1}$ used for 
normalization. $\mathrm{M}_{2}$ and $\mathrm{M}_{3}$ are used to collect data on NRM decay. The final two heating steps $\left(\mathrm{M}_{4}\right.$ and $\left.\mathrm{M}_{5}\right)$ are done again at $\mathrm{T}_{1}$ and $\mathrm{T}_{2}$ but cooled in a laboratory field in order to obtain pTRM for two different heating steps.

By normalizing the NRM demagnetization steps $\left(\mathrm{M}_{2}\right.$ and $\left.\mathrm{M}_{3}\right)$ and the pTRM acquisition steps $\left(\mathrm{M}_{5}-\mathrm{M}_{4}\right.$ and $\left.\mathrm{M}_{4}-\mathrm{M}_{3}\right)$ with $\mathrm{M}_{1}$, it is possible to create an Arai-like plot for the data that can be used to obtain a paleointensity estimate in the same manner as for the Thellier method (Tauxe, 2007).

In order to further reduce the number of heating steps required, Dekkers and Böhnel (2006) developed an alternate version of this method in which only one heating step was used for each specimen, and instead specimens were cooled in varying laboratory fields to provide data for comparison.

\section{Shaw method}

The Shaw method (Shaw, 1974) represents another attempt to reduce the number of heating steps required to determine paleointensity. This is accomplished by replacing many of the heating steps with steps involving ARM. In this approach, each specimen is subjected to AF demagnetization (a method in which specimens are demagnetized by being subjected to alternating decaying magnetic fields of progressively higher strength along each of its axes), after which it is imparted with an ARM along its $z$-axis. The ARM is then demagnetized. After these initial steps, the specimen is given a TRM by heating above its Curie temperature, the temperature below which a rock obtains remanence (Butler, 1992), and cooling in a known laboratory field. This TRM is then demagnetized. Finally, the initial phase of the method is repeated, in which the specimen is imparted with an ARM, and then AF demagnetized using the same steps in the previous ARM demagnetization.

An Arai plot can be created using the decay of the original NRM with the laboratory TRM, which can be confirmed using the ARM steps. This will result in a paleointensity estimate.

This method has evolved since its inception to add many more steps, including a second heating step and third round of ARM (Tsunakawa and Shaw, 1994), doubling the number of ARM steps (Rolph and Shaw, 1985), and adding an LTD step before each AF 
demagnetization (Yamamoto and Tsunakawa, 2005). While this has resulted in a more reliable method, it also reduces its usefulness as a means to avoid heating specimens.

The flaw in the Thellier method that the Shaw and multi-specimen methods fail to adequately account for is that it may take only one heating step to cause alteration in a specimen. So while reducing the heating steps to only one or two may lessen the problem, in some instances thermal alteration may be unavoidable when using a paleointensity method that involves any heating steps at all. This demonstrates the necessity for reliable techniques that can completely eliminate any heating steps.

\subsubsection{Non-heating Paleointensity Methods}

\section{A. Pseudo-Thellier method}

The Pseudo-Thellier method was originally developed for determining relative paleointensity in sedimentary rocks, whose remanence is not thermal in origin (Tauxe et al., 1995). In this method, the specimen is first subjected to AF demagnetization. The specimen is then given ARM in a stepwise manner using increasing AF fields in a constant known bias field.

This method, at least in methodology, is the closest approximation of the Thellier method without using heating steps. In place of using thermal demagnetization and pTRM acquisition data to create an Arai plot, loss of NRM during AF demagnetization are plotted against ARM acquisition to create a pseudo-Arai plot, which can be used in the same way to obtain a paleointensity estimate.

While initially developed for relative paleointensity in sediments, the PseudoThellier method has been applied more recently with success to determine absolute paleointensity estimates for igneous rocks and synthetic samples (de Groot et al., 2014; Yu et al., 2003). 


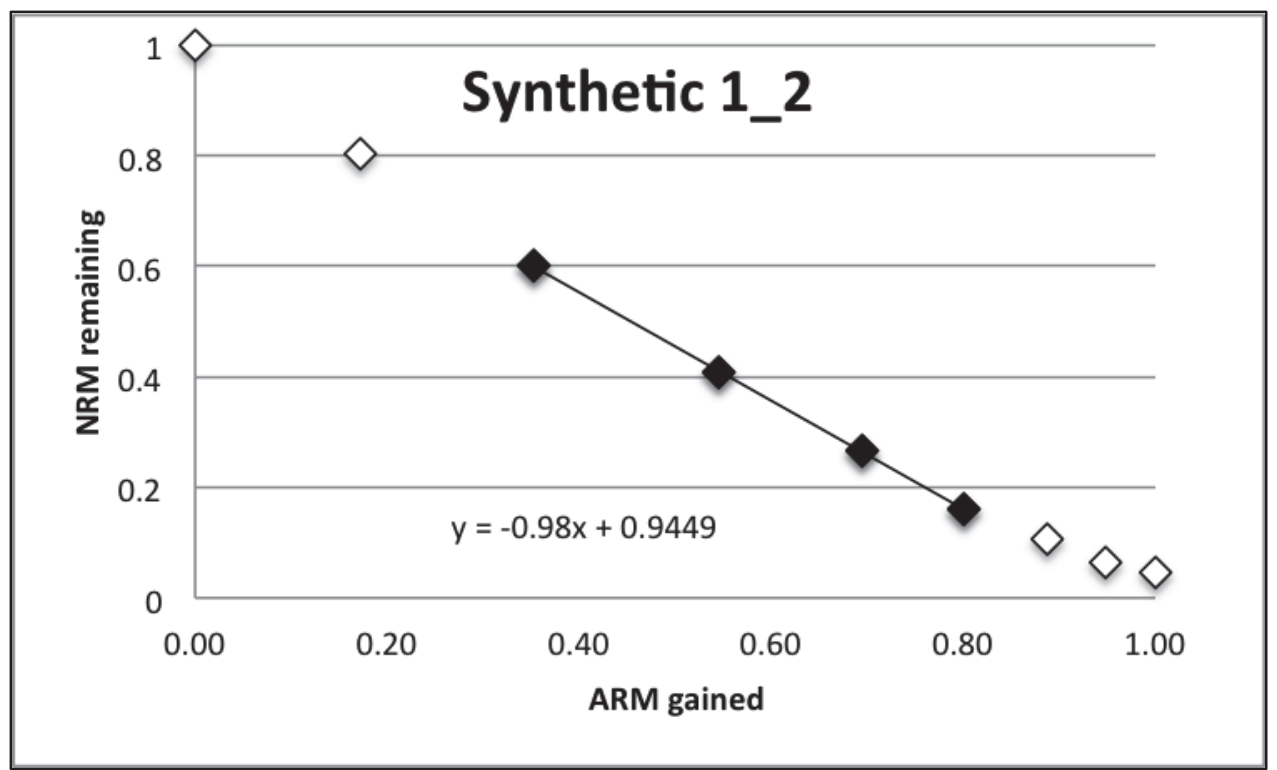

Figure 1.1: Arai plot for Pseudo-Thellier method analysis of a specimen comparing the loss of NRM versus the acquisition of ARM (both normalized). The paleointensity estimate is obtained by multiplying the slope of the plot by the ARM acquisition field.

\section{B. ARM method}

The ARM method, described by Yu (2010) and Lappe et al. (2013) is based on the comparison of the demagnetization spectra of the original NRM with an artificially created laboratory ARM. In this method, a specimen is first subjected to a stepwise AF demagnetization in order to analyze the demagnetization of the rocks' primary (and any secondary) remanence. It is then given ARM in a known field, and that ARM is subjected to a stepwise AF demagnetization. Lappe et al. (2013) determined that the bias field used for ARM does not affect the results obtained because ARM acquisition in increasing bias fields is linear, and the results will later be normalized using the bias field.

Once NRM and ARM demagnetization spectra have been obtained, the normalized decay curves of NRM and ARM are plotted against each other. The linear portion of this plot is selected, and the slope of the best fit is multiplied by the ARM bias field to obtain a paleointensity estimate.

To obtain a correct absolute paleointensity value, Lappe suggests that the result for natural samples should be divided by a correction factor $f$, where $0.7<f<1.2$. This results in the equation $\Delta \mathrm{NRM} / \Delta \mathrm{ARM} * B_{\text {bias }} / f_{\text {ARM. }}$. 


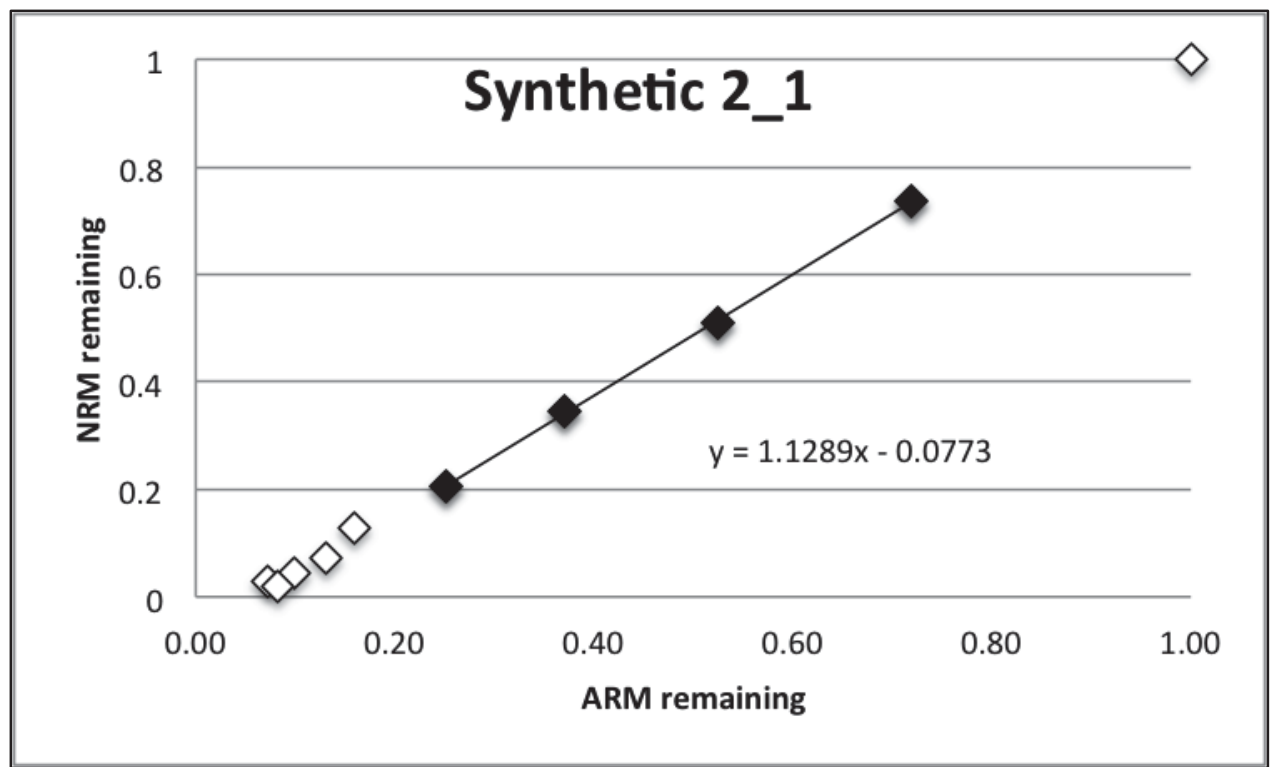

Figure 1.2: Arai plot for ARM method analysis of a specimen comparing the loss of NRM with the loss of ARM (both normalized). The paleointensity estimate is obtained by multiplying the slope of the plot by the ARM acquisition field.

\section{Trio of REM Methods}

The REM (ratio of equivalent magnetizations) method, as described by Acton et al. (2007) and Lappe et al. (2013), is similar to the ARM method in that involves comparing NRM and SIRM at different points in the demagnetization spectrum. In this method, a specimen is first subjected to AF demagnetization. The specimen is then magnetized to saturation in a strong field (often $1 \mathrm{~T}$ ) at room temperature, thus imparting SIRM. Finally, the specimen is once again subjected to AF demagnetization, providing a decay curve for SIRM.

There are three REM paleointensity methods: REM, REMc, and REM'. The simplest version, REM, is simply a ratio of the NRM to SIRM measured in a zero field. This method, however, does not take into account specimens that have a secondary directional component of remanence. While it may provide reliable results for unidirectional specimens, it is unlikely to be successful for specimens whose initial NRM contains two or more magnetization components.

The second method, REMc, involves estimating the ratio of NRM to SIRM at a point in the demagnetization spectrum that aligns with the specimen's characteristic direction of remanence. The REMc value can be selected for any AF step along the 
primary remanence direction, meaning there are many possible results. It is up to the scientist to choose the step to be used for determining the ratio.

The final REM method, REM', is the closest analogue to the ARM method. For this method, the decay curves of NRM and SIRM are compared over the portion of the AF spectrum representing the specimen's primary direction of remanence to obtain the ratio of NRM lost versus SIRM lost.

In all of the REM techniques, the ratios obtained can be compared for relative paleointensity values. Lappe et al. (2013) suggest that in order to use these methods for absolute paleointensity, a correction factor, $f$, should be applied. This value varies depending on the particular method of REM being used, and is not agreed upon in all of the literature. For example, Lappe et al. (2013) applies an $f$ of 3000 for REM, 2700 for REMc, and 1600 for REM', while Acton et al. (2007) applies an $f$ of 3000 for all three methods, and Gattacceca and Rochette (2004) apply an $f$ of 1000 for each method.

\section{Preisach method}

The most recently developed non-heating paleointensity method is the numerical model-based Preisach method (Muxworthy and Heslop, 2011). In this method, multiple types of data are entered into numerical model in the FORCinel program (Harrison and Feinberg, 2008), which uses a Preisach probability distribution to simulate the acquisition of TRM through heating.

For data input, the model requires an AF demagnetization spectrum as well as the specimen's SIRM. Additionally, it requires a first order reversal curve (FORC) diagram. A FORC diagram is a series of hysteresis loops generated at different points on the coercivity spectrum (Pike et al., 1999).

FORCinel uses the FORC diagram, normalized by SIRM, to generate a Presiach probability model representing the magnetic properties of the specimen. The program then uses this model to generate a simulated TRM acquisition curve over a range of different paleofields. By comparing the different TRM acquisition curves to the laboratory-obtained AF demagnetization curve, the user must manually select the 
paleofield that produces the best agreement between the two curves. This paleofield is the Preisach method estimate for paleointensity.

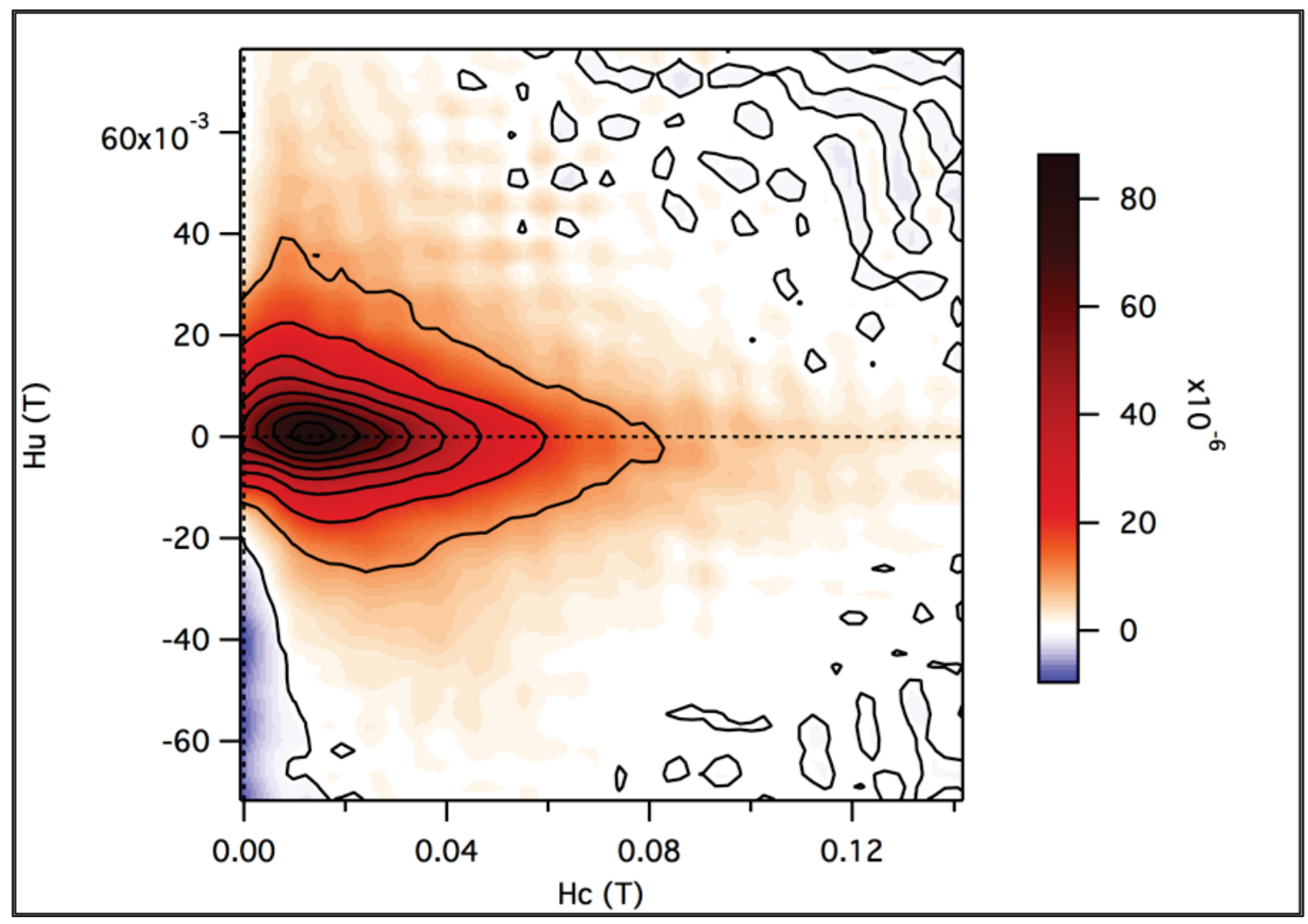

Figure 1.3: Example of a FORC diagram from a Lemptégy specimen. 
Table 1.1: Summary of main features of modern paleointensity methods.

\begin{tabular}{|c|c|c|c|c|}
\hline Method & $\begin{array}{l}\text { Initial } \\
\text { Type of } \\
\text { Demag }\end{array}$ & $\begin{array}{l}\text { Method of } \\
\text { Remagnetization }\end{array}$ & $\begin{array}{l}\text { Method of } \\
\text { Comparison }\end{array}$ & $\begin{array}{l}\text { Number } \\
\text { of } \\
\text { Heating } \\
\text { Steps }\end{array}$ \\
\hline $\begin{array}{l}\text { Theller-Thellier } \\
\text { (Thellier and Thellier, } \\
\text { 1959) }\end{array}$ & Thermal & $\begin{array}{l}\text { Cooling from high } \\
\text { temperature }\end{array}$ & $\begin{array}{l}\text { NRM lost vs. } \\
\text { pTRM gained }\end{array}$ & Many \\
\hline $\begin{array}{l}\text { Multispecimen } \\
\text { (Dekkers and Böhnel, } \\
\text { 2006; Hoffman et al., } \\
\text { 1989) }\end{array}$ & $\mathrm{AF}$ & $\begin{array}{l}\text { Cooling from high } \\
\text { temperature }\end{array}$ & $\begin{array}{l}\text { NRM lost vs. } \\
\text { pTRM gained }\end{array}$ & 1 \\
\hline $\begin{array}{l}\text { LTD-DHT Shaw } \\
\text { (Shaw, 1974; } \\
\text { Yamamoto and } \\
\text { Tsunakawa, 2005) }\end{array}$ & $\mathrm{LDT}+\mathrm{AF}$ & ARM & $\begin{array}{l}\text { ARM lost vs. } \\
\text { TRM lost }\end{array}$ & 2 \\
\hline $\begin{array}{l}\text { Pseudo-Thellier } \\
\text { (Tauxe et al., 1995) }\end{array}$ & $\mathrm{AF}$ & ARM (stepwise) & $\begin{array}{l}\text { NRM lost vs. } \\
\text { pARM gained }\end{array}$ & 0 \\
\hline $\begin{array}{l}\text { ARM } \\
\text { (Markert and Heller, } \\
\text { 1972; Yu, 2010) }\end{array}$ & $\mathrm{AF}$ & ARM & $\begin{array}{l}\text { NRM lost vs. } \\
\text { ARM lost }\end{array}$ & 0 \\
\hline $\begin{array}{l}\text { REM } \\
\text { (Kletetschka et al., } \\
\text { 2003) }\end{array}$ & $\mathrm{AF}$ & Pulse Magnetizer & $\begin{array}{l}\text { NRM vs. } \\
\text { SIRM }\end{array}$ & 0 \\
\hline $\begin{array}{l}\text { REMc } \\
\text { (Acton et al., 2007) }\end{array}$ & $\mathrm{AF}$ & Pulse Magnetizer & $\begin{array}{l}\text { NRM vs. } \\
\text { SIRM (at any } \\
\text { matching AF } \\
\text { step) }\end{array}$ & 0 \\
\hline $\begin{array}{l}\text { REM' } \\
\text { (Gattacceca and } \\
\text { Rochette, 2004) }\end{array}$ & $\mathrm{AF}$ & Pulse Magnetizer & $\begin{array}{l}\text { NRM lost vs. } \\
\text { SIRM lost }\end{array}$ & 0 \\
\hline $\begin{array}{l}\text { Preisach } \\
\text { (Muxworthy and } \\
\text { Heslop, 2011) }\end{array}$ & $\mathrm{AF}$ & $\mathrm{n} / \mathrm{a}$ & $\begin{array}{l}\text { Preisach } \\
\text { numerical } \\
\text { model using } \\
\text { SIRM- } \\
\text { normalized } \\
\text { FORC } \\
\text { diagram }\end{array}$ & 0 \\
\hline
\end{tabular}




\subsection{Geologic Setting}

Le Vulcan de Lemptégy is located in the Auvergne region of France, approximately $12 \mathrm{~km}$ northwest of the city of Clermont-Ferrand, in the commune of Saint-Ours (Figure 1.4). The volcano is part of the Chaîne des Puys, a chain of 100 ka to 8 ka volcanic edifices in the Massif Central (Boivin et al., 2004). The volcano can be found at the coordinates $45^{\circ} 49^{\prime} 05^{\prime \prime} \mathrm{N}, 2^{\circ} 56^{\prime} 49^{\prime \prime} \mathrm{E}$. The focus of this study is Lemptégy 2 , one of the two eruptive edifices that make up Lemptégy volcano.

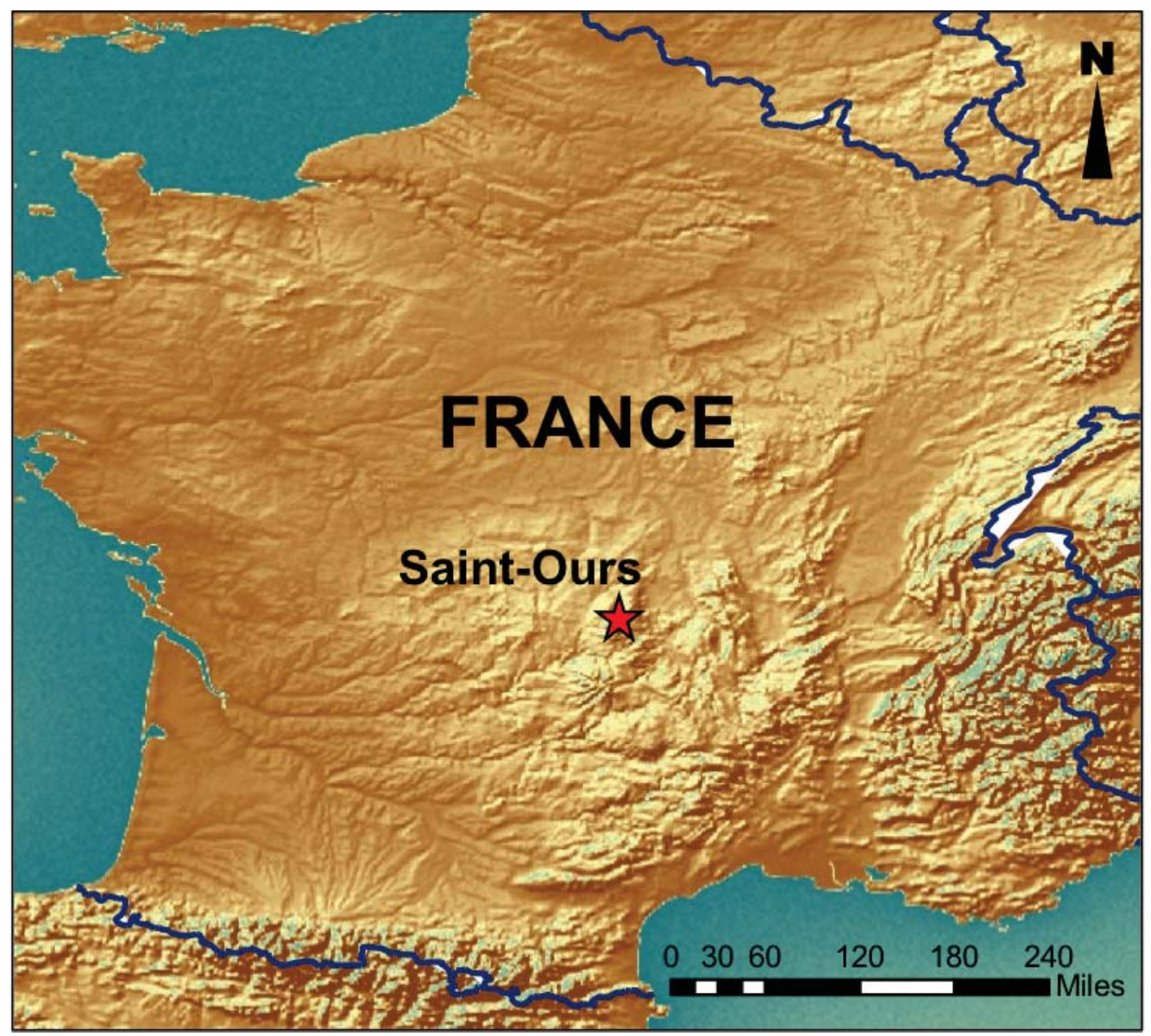

Figure 1.4: Map of site location.

\section{Chaîne des Puys}

The Chaîne des Puys is an alignment of around 80 monogenetic volcanic edifices, including maars, cinder cones, lava domes, and explosion craters. The chain is around 40 $\mathrm{km}$ long, aligned from north to south, and located in the Massif Central, a larger volcanic 
region in central France (Delcamp et al., 2013). Volcanism in the Chaîne des Puys can be dated back at least five million years, though all present volcanoes in the region are younger than 200,000 years old, with the most recent eruption happening 7,600 years ago (Boivin et al., 2009).

\section{Volcan de Lemptégy}

Lemptégy volcano is a cinder cone formed 32,000 years ago from primarily Strombolian eruptive mechanisms (Boivin et al., 2009). The volcanic consists of two separate eruptive centers from two distinct eruptive events, with the earlier event forming Lemptégy 1 to the east and the later event forming Lemptégy 2 to the west (De Goër de Hervé et al., 1999). Radiometric dating of material from both cones indicates that they were erupted within a short time frame, however, a $1 \mathrm{~cm}$ thick weathered layer between deposits from Lemptégy 1 and 2 indicates that at least some time passed between eruptive events (Delcamp et al., 2013).

Lemptégy is of interest as a site of study largely due to human impacts on the cinder cone. Quarrying of the site began in the early 1800s (de Ramond, 1815), and the volcano was quarried continuously from 1946 until 2007, with volcanologists from the Laboratorie de Magma et Volcans providing input starting in the 1980s to assure the preservation of the geologically important aspects of the site (Delcamp et al., 2013). As a result of this intervention, structures such as dikes and magma conduits that normally only exist in the subsurface are exposed for study.

\section{Lemptégy 2}

Lemptégy 2, formed by the second eruptive event at the Lemptégy complex, is a basaltic trachy-andesite to trachy-andesite cinder cone (Boivin et al., 2009). Deposits from the cone are mostly well-sorted, chemically homogenous scoriaceous lapilli and bombs. The lava flows were deposited in multiple phases and in many different directions from the vent, resulting in the emplacement of cryptodomes. Lemptégy 2's dike system was influenced by the already present Lemptégy 1, which acted as a buttress during the 
emplacement of the dikes. The majority of these dikes trend from northeast to southwest (Delcamp et al., 2013).

The previously mentioned quarrying of the cinder cone allows for the visibility of the respective feeder dikes of many of the lava flows, making it a potentially useful site for paleointensity studies.

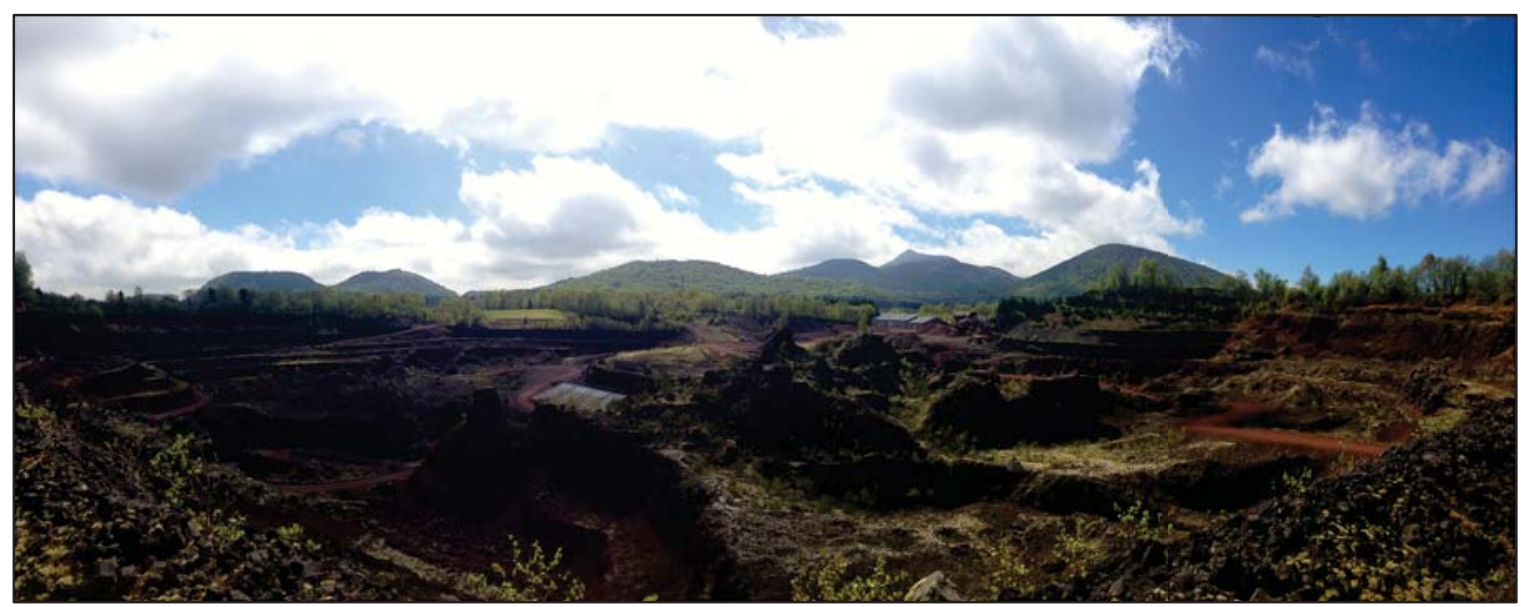

Figure 1.5: Lemptégy Volcano. The conduit of Lemptégy 2 is visible to the center-right of the image (Photo credit: author)

\section{Methods}

\subsection{Field Sampling}

Fieldwork was conducted at the site over the course of two days in May 2013. Samples were collected for this (and other) studies, and field observations were made to supplement the sample data. Samples were taken from multiple sites on both Lemptégy 1 and 2. Ultimately, three particular sites form Lemptégy 2 were selected for this study based on their feeder dike/lava flow relationship, that sites LG24 and LG26 were two points on a lava flow fed by dike LG21.

11 sample cores were collected from both the east and west margins of the dike (LG21E and LG21W), 12 cores were collected from the lava flow far from the dike (LG26), and 13 cores were collected from the lava flow close to the dike (LG24). The cores were drilled by Michael Petronis (New Mexico Highlands University) using an adapted gasoline powered chainsaw with a non-magnetic, diamond-tipped bit. The cores 
were oriented with an adapted Brunton compass, clinometer, and (when possible) sundial. In total, 47 cores, each $25 \mathrm{~mm}$ in diameter and approximately 5 to $15 \mathrm{~cm}$ in length, were collected for rock magnetic, magnetic mineralogy, microscopy, and paleointensity analyses.

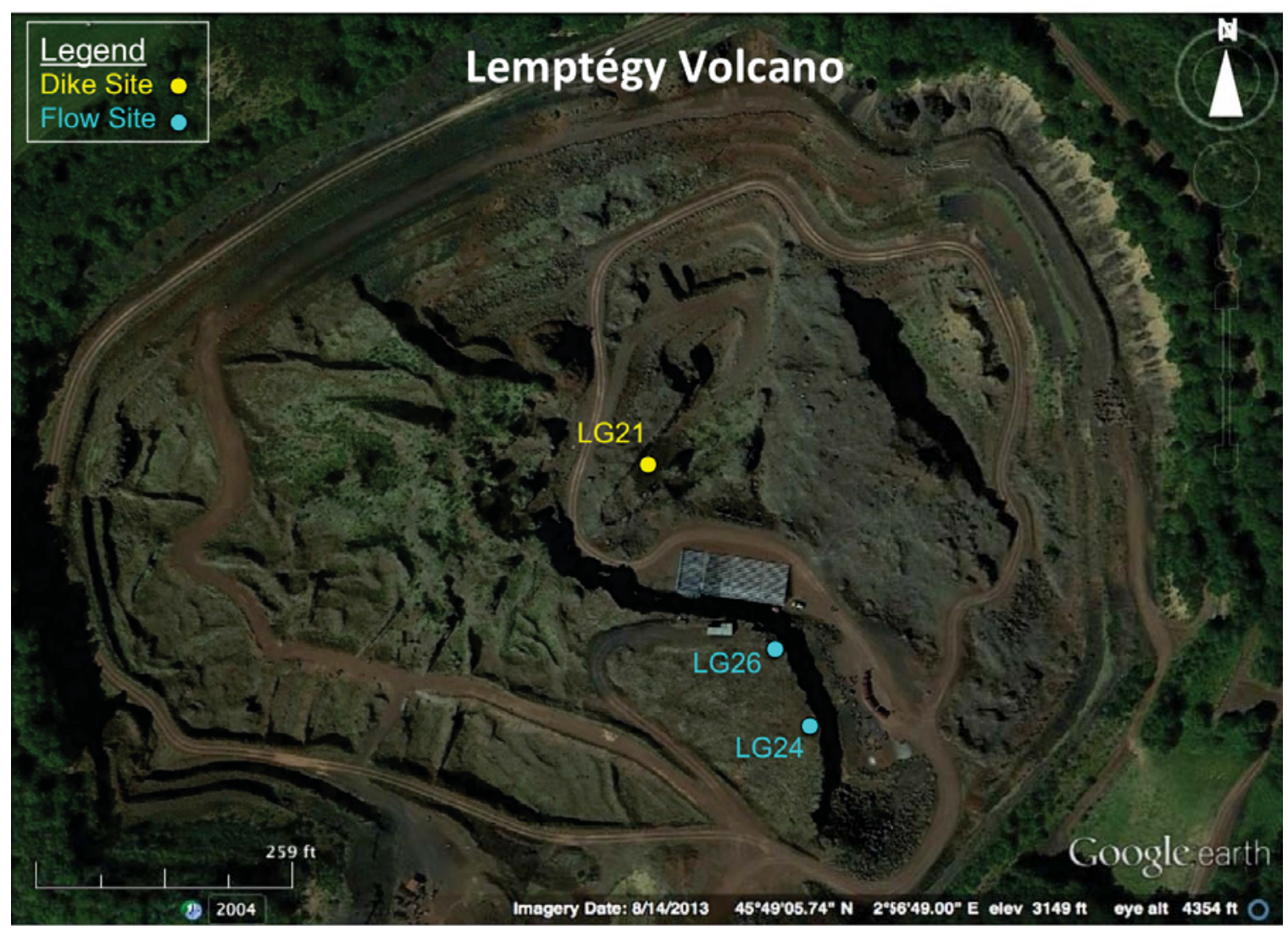

Figure 2.1: Map of Lemptégy Volcano with site locations marked. Map was created using satellite imagery from Google Earth. 


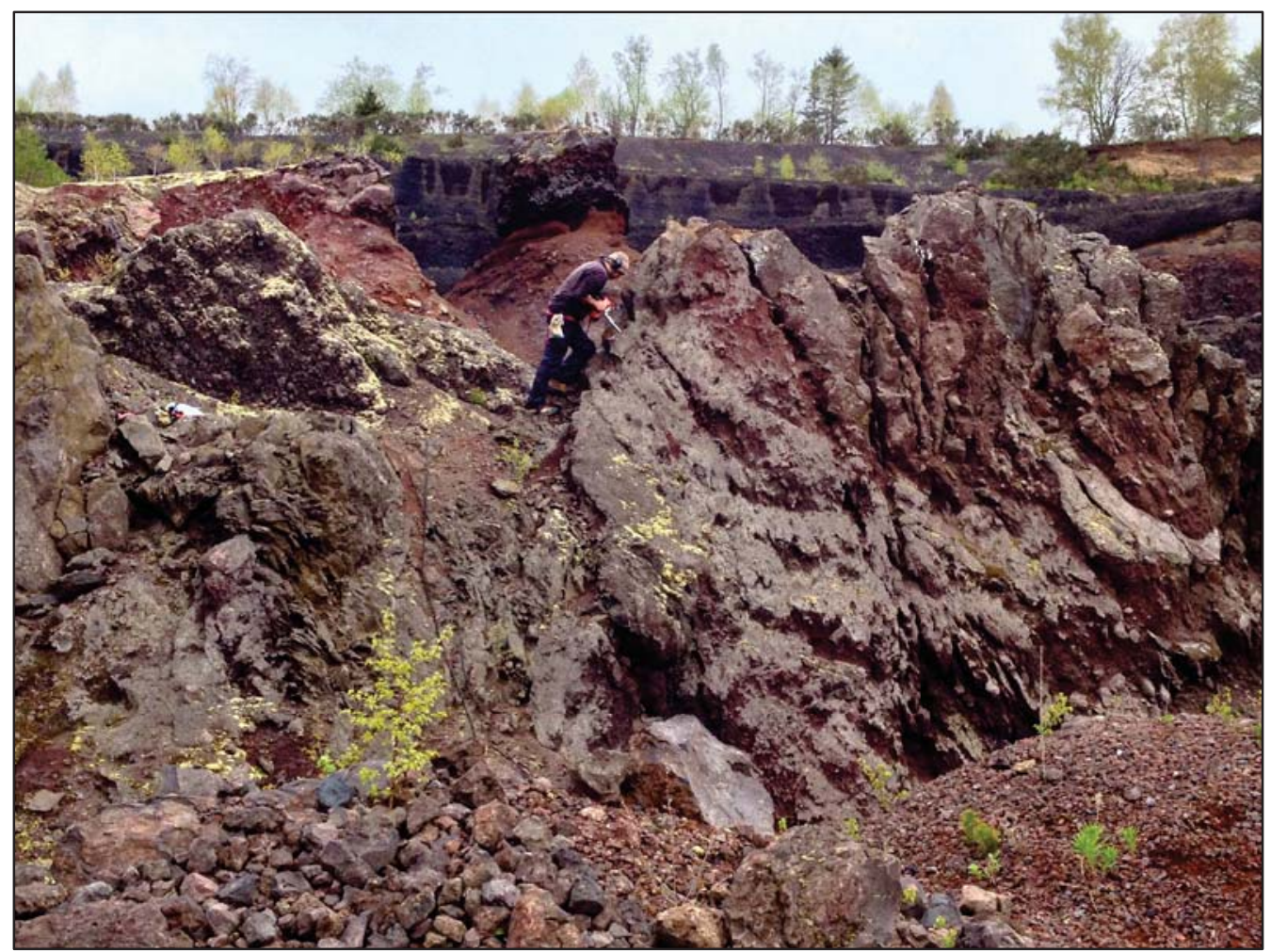

Figure 2.2: Drilling cores at Lemptégy Volcano (Photo credit: author)

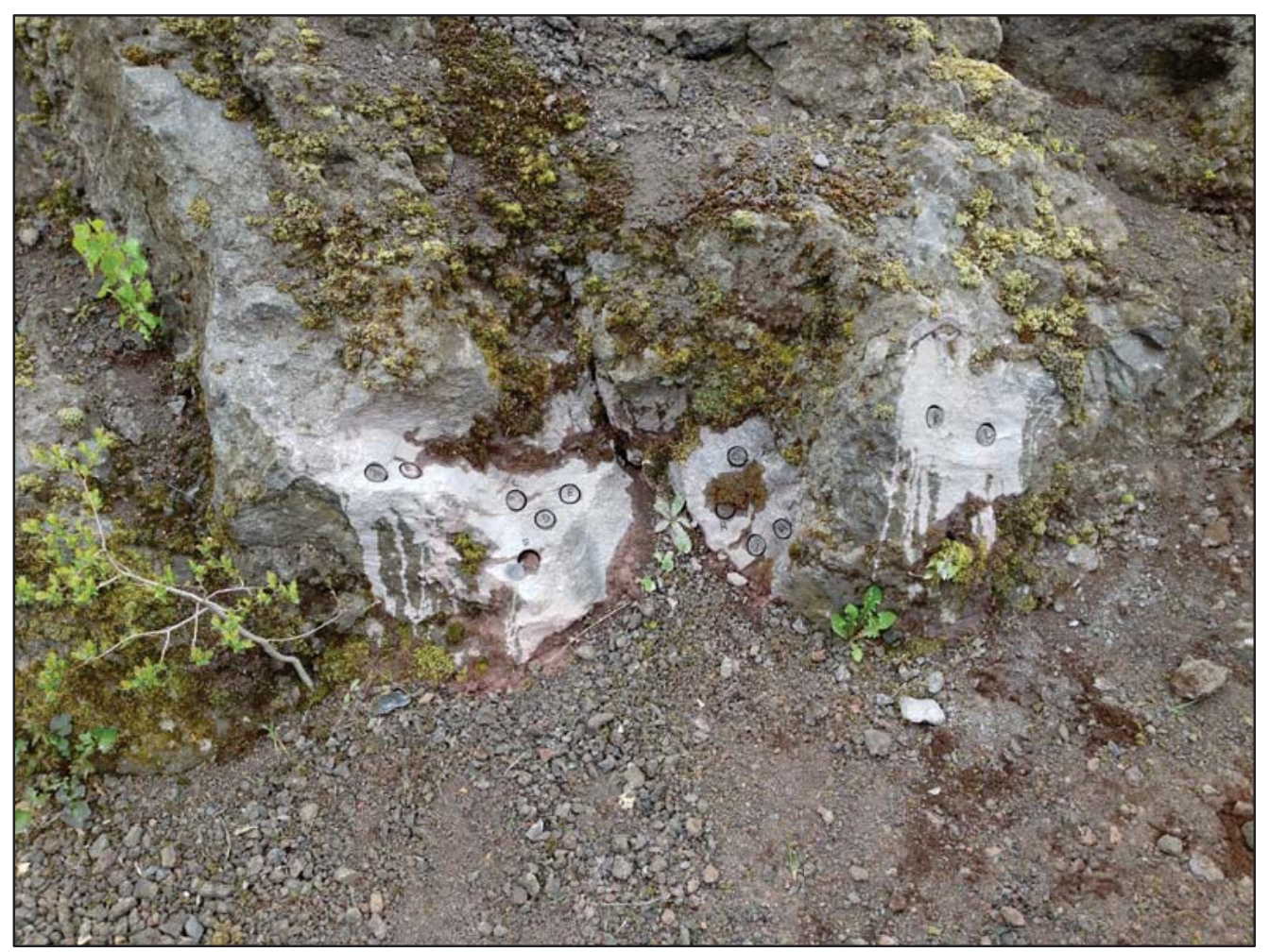

Figure 2.3: Cores drilled at Lemptégy site prior to orienting (Photo credit: author) 


\subsection{Sample Preparation}

The cores collected during field sampling were used to create the appropriate type of specimen for each test to be run.

A thin sliver was cut from the bottom of each sample and used to form two types of specimens. Each sliver was crushed with an iron or brass mortar and pestle, and a smaller chip of approximately $1 \mathrm{~mm}^{3}$ with the most spherical shape possible was collected for use in the alternating gradient magnetometer. The remainder of the sliver was ground into powder for use in thermomagnetic susceptibility experiments. The mass of both of these types of specimens was measured, and, for the powder, an amount between 0.3 and $0.5 \mathrm{~g}$ was used.

When possible, two $11 \mathrm{~mm}$ thick cylinders were cut from the remainder of each core. Specimens were cut from the bottom of the core towards the top to avoid any potential weathering effects that might be present in a specimen cut from near the surface. This was possible in all but one core, resulting in 92 specimens created from 47 samples. The specimens were stored in a magnetically shielded room to prevent any additional viscous remanent magnetization (VRM). The mass and volume of each specimen was measured. 


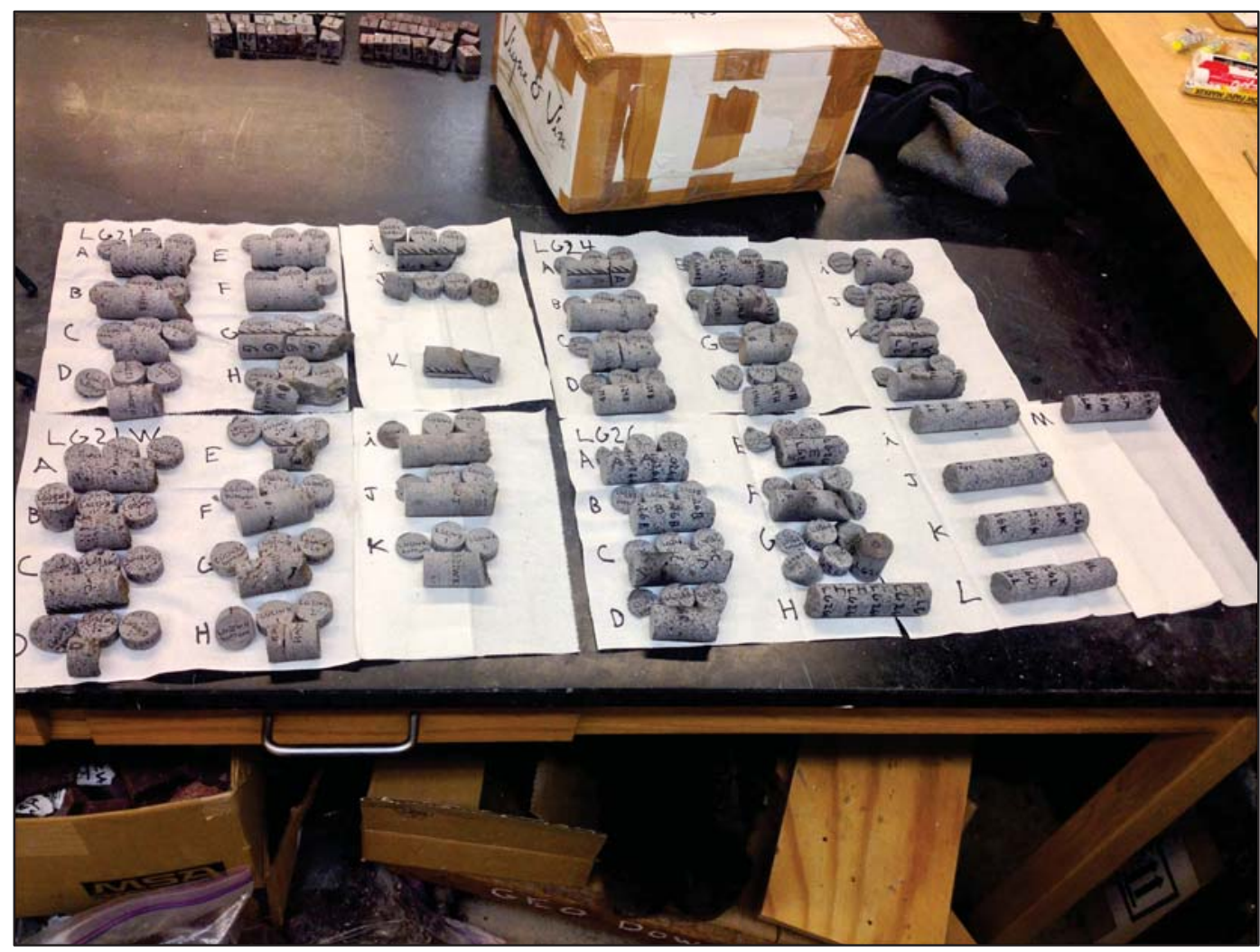

Figure 2.4: Cylindrical specimens cut from Lemptégy sample cores (Photo credit: author)

The synthetic specimens were provided by Evgeniy Kulakov of Michigan Technological University. The specimens were created from magnetite powders of varying grain size. Five different types of specimens were used, each with a different combination of average grain sizes: Single Domain $(0.35 \mu \mathrm{m}), 1(0.75 \mu \mathrm{m}), 2(1.5 \mu \mathrm{m}), 3$ (a mix of the grain sizes), and Multi-domain (100-400 $\mu \mathrm{m})$. The specimens were given an artificial TRM by cooling from a temperature of $700^{\circ} \mathrm{C}$ in a laboratory field of $50 \mu \mathrm{T}$. The specimens were broken into smaller pieces to create chips weighing between 0.010 and $0.021 \mathrm{~g}$ for use in all paleointensity experiments.

\subsection{Rock Magnetism}

\subsubsection{Hysteresis Properties}

A MicroMag Model 2900 Alternating Gradient Magnetometer (AGM) was used to measure hysteresis loops and backfield demagnetization remanence curves for the 1 
$\mathrm{mm}^{3}$ chip specimens from selected sites. The AGM functions by alternating between an ac and dc magnetic field and sensing the change in amplitude vibration with a piezoelectric transducer. This allows for the measurement of magnetic moment versus applied magnetic field (Graham, 2000).

Each $1 \mathrm{~mm}^{3}$ specimen was placed on a silica probe using silica glue. The probe was cleaned with alcohol between each specimen. The AGM was calibrated with an yttrium iron garnet sphere standard with a known magnetic moment of 77.64 memu and by measuring the empty silica probe. These calibrations were used to make corrections to the hysteresis loops obtained. Corrections for dia- and paramagnetic effect were also applied. Hysteresis loops and remanence curves obtained were analyzed using MicroMag AGM software.

\subsubsection{Thermomagnetic Curves}

Thermomagnetic properties of specimens were tested using an AGICO (Advanced Geosciences Instruments Company) MFK1-FA Kappabridge with a CS-3 Furnace Apparatus for high temperature tests and a CS-L Cryostat for low temperature tests. Specimens used were 0.3-0.5 g of powder from selected sites.

The experiments were run in three steps: a low temperature heating curve, a high temperature heating and cooling curve, and a second low temperature heating curve. The probe and sample test tube were cleaned with alcohol between specimens.

For the first low temperature curve, the probe and specimen were inserted into the cryostat and lowered to a temperature of $-192^{\circ} \mathrm{C}$ by adding liquid nitrogen to the cryostat. Once the specimen reached a temperature of $-192^{\circ} \mathrm{C}$ the liquid nitrogen was removed from the cryostat using argon gas. The susceptibility of the specimen was then measured incrementally as it was heated gradually to $5^{\circ} \mathrm{C}$.

For the high temperature curve, the probe and specimen were inserted into the furnace apparatus and heated, starting at room temperature. The susceptibility of the specimen was measured incrementally between $40^{\circ} \mathrm{C}$ and $700^{\circ} \mathrm{C}$, then measured again as the specimen cooled from $700^{\circ} \mathrm{C}$ to $40^{\circ} \mathrm{C}$. During heating the specimen was kept in an argon gas environment to prevent oxidation. 
The second low temperature curve was created by reinserting the specimen and probe back into the cryostat and repeating the procedure from the first low temperature curve.

In some instances, low temperature curves were not required, in which case only the procedure for the high temperature curve was followed. Additionally, in some instances, information about heating and cooling curves to lower temperatures was desired. In these instances, the procedure for the high temperature curve was followed with a different peak temperature replacing $700^{\circ} \mathrm{C}$, such as $400^{\circ} \mathrm{C}$ or $580^{\circ} \mathrm{C}$.

Thermomagnetic curves were analyzed with AGICO Cureval8 software.

\subsection{Paleomagnetic Analysis}

Thermal demagnetization was conducted in order to isolate the characteristic remanent magnetism (ChRM) from the natural remanent magnetism (NRM). NRM is the total remanence that a specimen has acquired prior to lab analysis. NRM can be divided into primary and secondary magnetization components. By using demagnetization techniques, it is possible to eliminate most of the secondary remanence acquired after the rock's initial formation, resulting in ChRM (Butler, 1992).

To do this, two specimens from each site were subjected to low temperature demagnetization (LTD). The specimens were placed in liquid nitrogen for 15 minutes, then returned to room temperature in a magnetically shielded room. This step was repeated once, with the NRM measured after each LTD. This step aims to remove most of the multidomain remanence from the specimens (Schmidt, 1993).

Following LTD, the specimens were heated to $670^{\circ} \mathrm{C}$ in a stepwise manner, using intervals of $100^{\circ} \mathrm{C}$ between $0^{\circ} \mathrm{C}$ and $400^{\circ} \mathrm{C}$ and intervals of $15^{\circ} \mathrm{C}$ between $400^{\circ} \mathrm{C}$ and $670^{\circ} \mathrm{C}$. NRM of each specimen was measured between each heating step.

The direction of ChRM was also determined using alternating field (AF) demagnetization. The specimens were subjected to an alternating magnetic field using a 2G Enterprises 760-R Superconducting Magnetometer. The fields were applied in steps: from $0 \mathrm{mT}$ to $15 \mathrm{mT}$ in intervals of $2.5 \mathrm{mT}$, from $15 \mathrm{mT}$ to $50 \mathrm{mT}$ in intervals of $5 \mathrm{mT}$, 
and from $50 \mathrm{mT}$ on in intervals of $10 \mathrm{mT}$ to between 90 and $120 \mathrm{mT}$ (the point at which ideally at least $90 \%$ of the NRM had been removed).

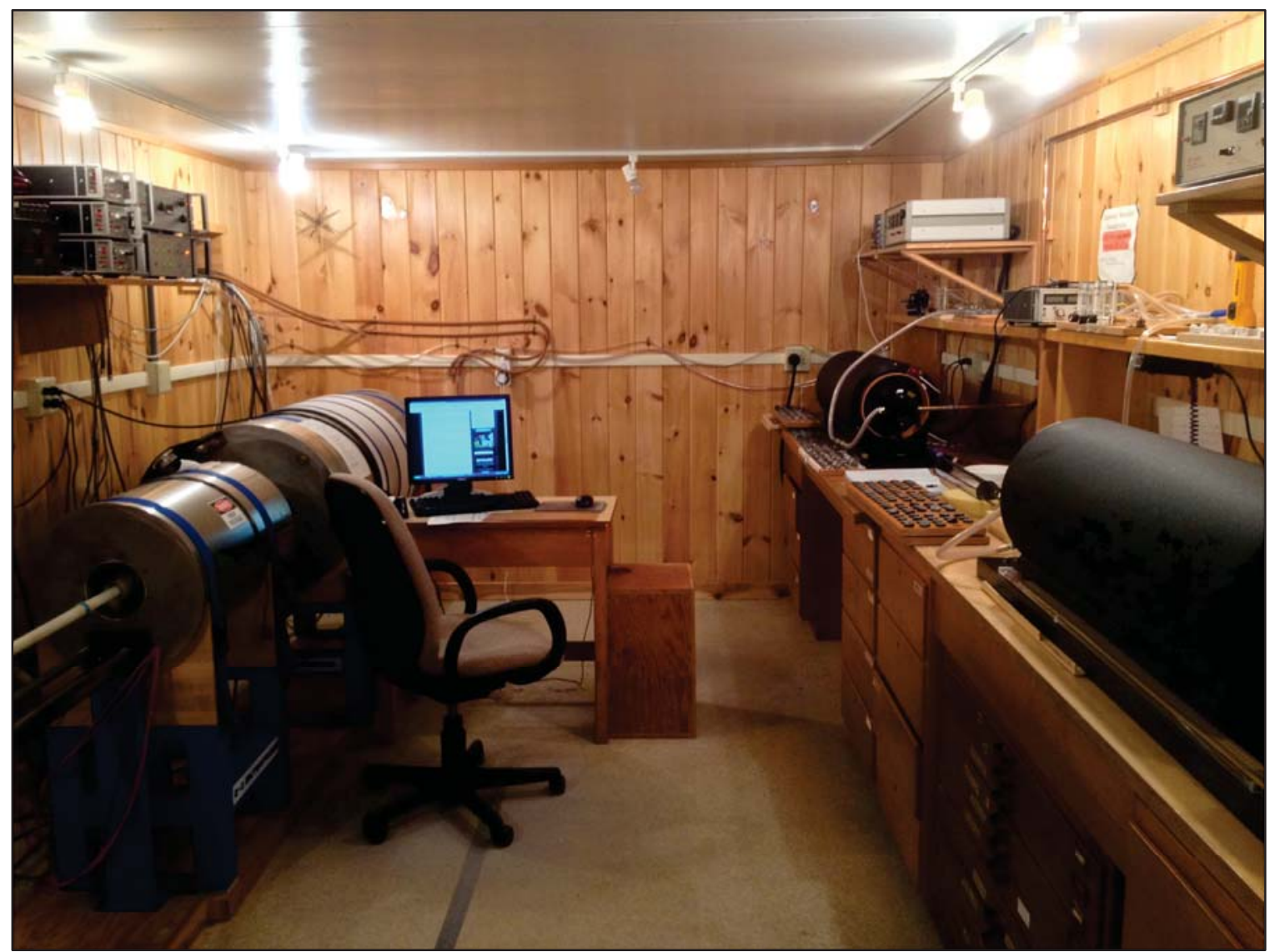

Figure 2.5: The magnetically shielded room in the Michigan Technological University Earth Magnetism Laboratory. The room contains the 2G Superconducting Rock Magnetometer on which measurements were taken (Photo credit: author)

\subsection{Paleointensity Tests}

The results of the rock magnetism tests (see Section 2.3) showed that that chemical alteration in the Lemptégy basalts occurs at temperatures significantly below their magnetization unblocking temperature. As a result, it was determined that none of these classic paleointensity methods were viable for the Lemptégy samples since the heating-induced alteration would produce unreliable results. As a result, less conventional non-heating paleointensity methods were utilized. 
The methods used for this study include the Pseudo-Thellier, ARM, REM, REMc, REM', and Preisach methods, all described above. NRM, ARM, and SIRM demagnetization curves as well as the ARM acquisition curve were obtained using a $2 \mathrm{G}$ Enterprises 760-R Superconducting Magnetometer. In order to obtain all data from the same specimen, the following protocol was strictly employed: AF demagnetization, ARM acquisition, ARM demagnetization, SIRM acquisition, SIRM demagnetization.

ARM for the Pseudo-Thellier method was imparted in a laboratory field of $50 \mu \mathrm{T}$ for all specimens up to the same AF step used in demagnetization using a $2 \mathrm{G}$ ARM Magnetizer Model 615. ARM for the ARM method was imparted in a laboratory field of $50 \mu \mathrm{T}$ for synthetic specimens and $300 \mu \mathrm{T}$ for natural specimens. Specimens were imparted with SIRM in a 1 T field using a Sapphire Instruments SI-6 Pulse Magnetizer. FORC diagrams to be used in the Preisach method were measured using a MicroMag Model 2900 Alternating Gradient Magnetometer (AGM) from chips taken from each cylindrical specimen. For the synthetic specimens, the same chip was used both for all demagnetization/acquisition curves as well as measurement of magnetic hysteresis properties and FORC diagrams.

For the trio of REM methods, correction factors determined by Lappe et al. (2013) were used to obtain paleointensity estimates from the measured REM ratios: 3000 for REM, 2700 for REMc, and 1600 for REM'.

\subsection{Microscopy}

\subsubsection{Sample Preparation}

Samples used for both reflected light and scanning electron microscopy were cut from selected cores following the preparation of samples for magnetic testing. Three 10 mm thick cylinders each were cut from one representative core from each site. To avoid any unintentional tilt on the surface of the specimens, each specimen was glued to a glass slide with epoxy, grinded flat on the top, and cut off the slide using diamond-tipped grinders and saws.

Each specimen was polished manually on one side using increasing grade of aluminum powder $(1000 \mu \mathrm{m}, 600 \mu \mathrm{m})$ and mechanically with diamond paste $(100 \mu \mathrm{m}, 3$ 
$\mu \mathrm{m}, 1 \mu \mathrm{m}, 0.25 \mu \mathrm{m})$. Between polishing, specimens were cleaned using a sonicator. During sample preparation, kerosene was used as coolant, lubricant, and fluid for cleaning specimens.

\subsubsection{Scanning Electron Microscopy}

Specimens were analyzed using a FEI Philips XL 40 Environmental Scanning Electron Microscope (ESEM). All specimens were observed at an initial working distance of $10 \mathrm{~mm}$ and accelerating voltage of $15 \mathrm{kV}$. Minerals were observed at magnification between 25x and 2500x. All samples were coated in carbon for conductivity prior to use in the ESEM.

Observations focused on magnetic minerals, primarily using the environmental backscatter detector. Those minerals appear lightest in shade under the EBSD. Energy dispersive spectrometry (EDS) was used to analyze x-ray spectra of the magnetic minerals present in the specimens. Locations of notable mineral crystals were recorded so those crystals could be viewed again during future sessions.

After initial sessions for acquiring images and x-ray spectra of magnetic minerals, each specimen was heated to $600^{\circ} \mathrm{C}$. After heating, specimens were observed again using the ESEM with particular focus on crystals photographed during the initial sessions to see what alteration had taken place due to heating. 


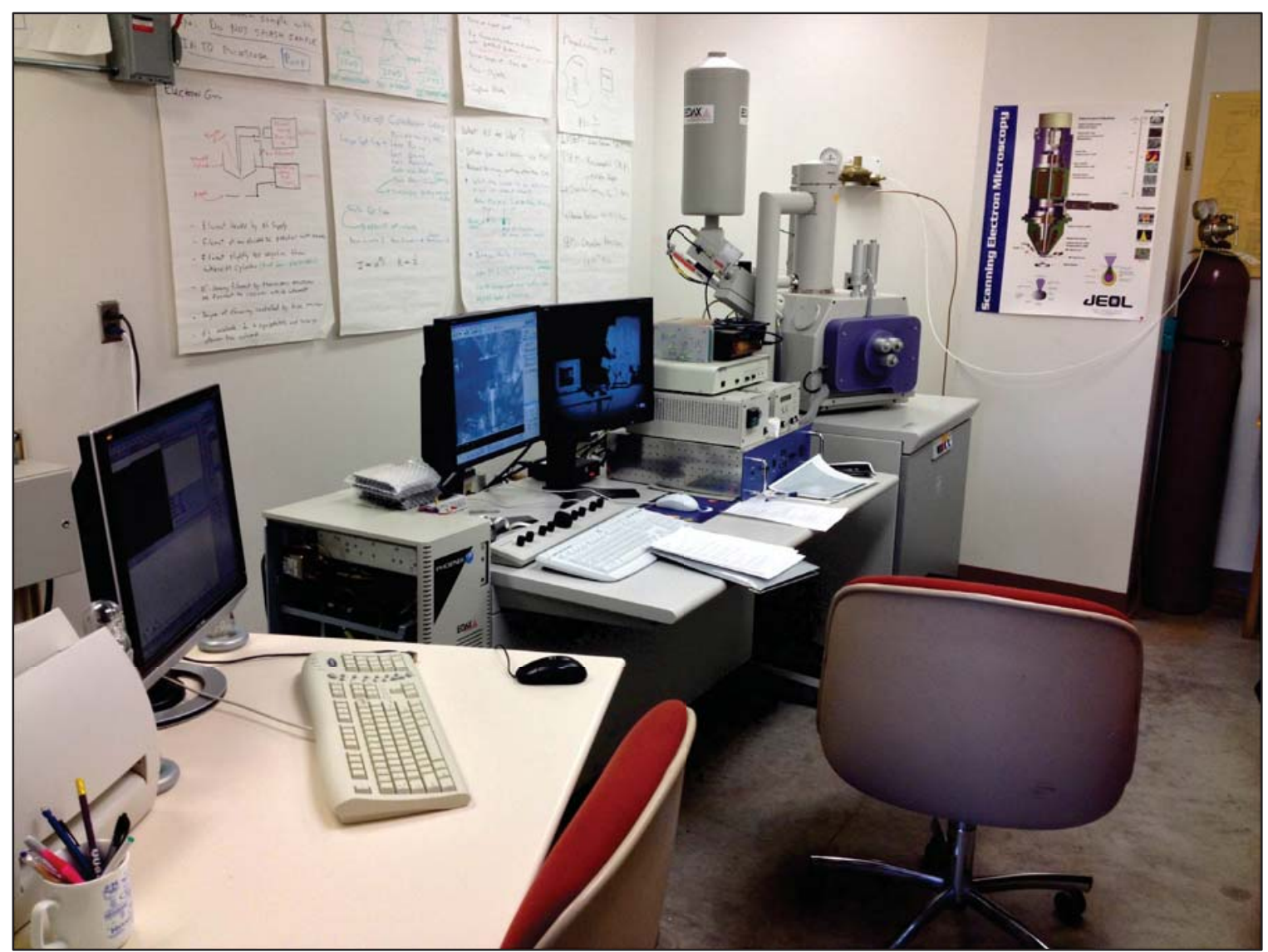

Figure 2.6: The FEI Philips XL 40 SEM located in Michigan Technological University's Minerals and Materials Engineering Building (Photo credit: author)

\section{Results}

\subsection{Rock Magnetism}

\subsubsection{Hysteresis Properties}

While hysteresis loops produced by the different sites exhibited varying degrees of squareness, a ratio of saturation remanence (Mrs) to saturation magnetization (Ms) that indicates the tendency of a grain to demonstrate single domain magnetic properties (Tauxe et al., 2002), all displayed as standard hysteresis loops. No potbellies or wasp waists, which would indicate a higher likelihood of two distinct phases with two distinct coercivities (Tauxe et al., 1996), were observed. Squareness in the flow sites (LG24 and LG26) was generally lower than that in the dike sites (LG21E and LG21W), indicating a higher likelihood of multi-domain grains (Tauxe et al., 2002). 
The magnetic hysteresis data plotting system devised by Day et al. (1977) can be used to analyze the relationship of squareness (the ratio of saturation remanent magnetization, $\mathrm{M}_{\mathrm{rs}}$, to saturation magnetization, $\mathrm{M}_{\mathrm{s}}$ ) to the ratio of coercive remanence $\left(\mathrm{H}_{\mathrm{cr}}\right)$ to coercive force $\left(\mathrm{H}_{\mathrm{c}}\right)$. The placement of data points representing individual specimens on the Day plot can be used to assess the single or multi domain nature of those specimens (Dunlop, 2002). 

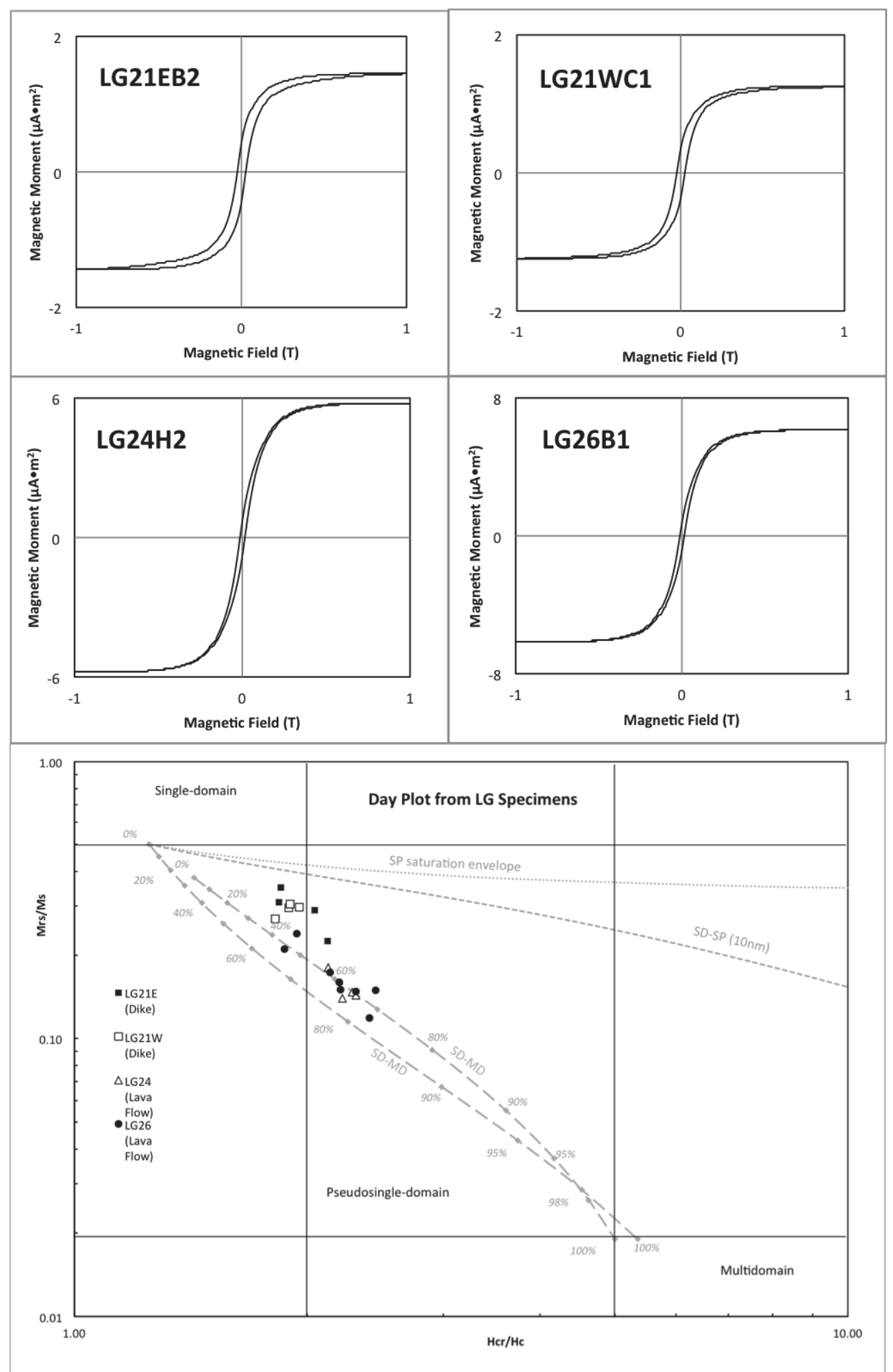

Figure 3.1: Hysteresis data for Lemptégy specimens. One representative hysteresis loop is shown from each site. The placement of the points on the day plot demonstrates that specimen's tendency toward single or multi domain properties. Abbreviations: Hc, coercivity; Hcr, coercivity of remanence; Mrs, saturation remanence; Ms, saturation magnetization; SD, single-domain; 
PSD, pseudosingle-domain; MD, multidomain; SP, superparamagnetic. Models are also shown for superparamagnetism and SD-SP, SD-MD mixtures from Dunlop (2002).

The Day plot (Figure 3.1) indicates that the dike samples are closer to singledomain in nature, while the lava samples have more multidomain grains. Nonetheless, even the samples that plot further from the single domain region of the plot still plot within the pseudosingle-domain portion of the plot, a favorable result for performing further experiments.

A separate test in which specimens were heated between AGM measurements was performed on specimens from each site to determine their suitability for heating in low temperature paleointensity experiments. The results can be seen in Figure 3.2.

This Day plot shows some change in hysteresis properties following a heating to $530^{\circ} \mathrm{C}$, indicating that some amount of thermal alteration in samples from these sites has begun by $530^{\circ} \mathrm{C}$. A similar experiment was carried out with heating to $400^{\circ} \mathrm{C}$. The results seen in Figure 3.3 show that even at temperatures as low as $400^{\circ} \mathrm{C}$ some small amount of thermal alteration has begun to take place.

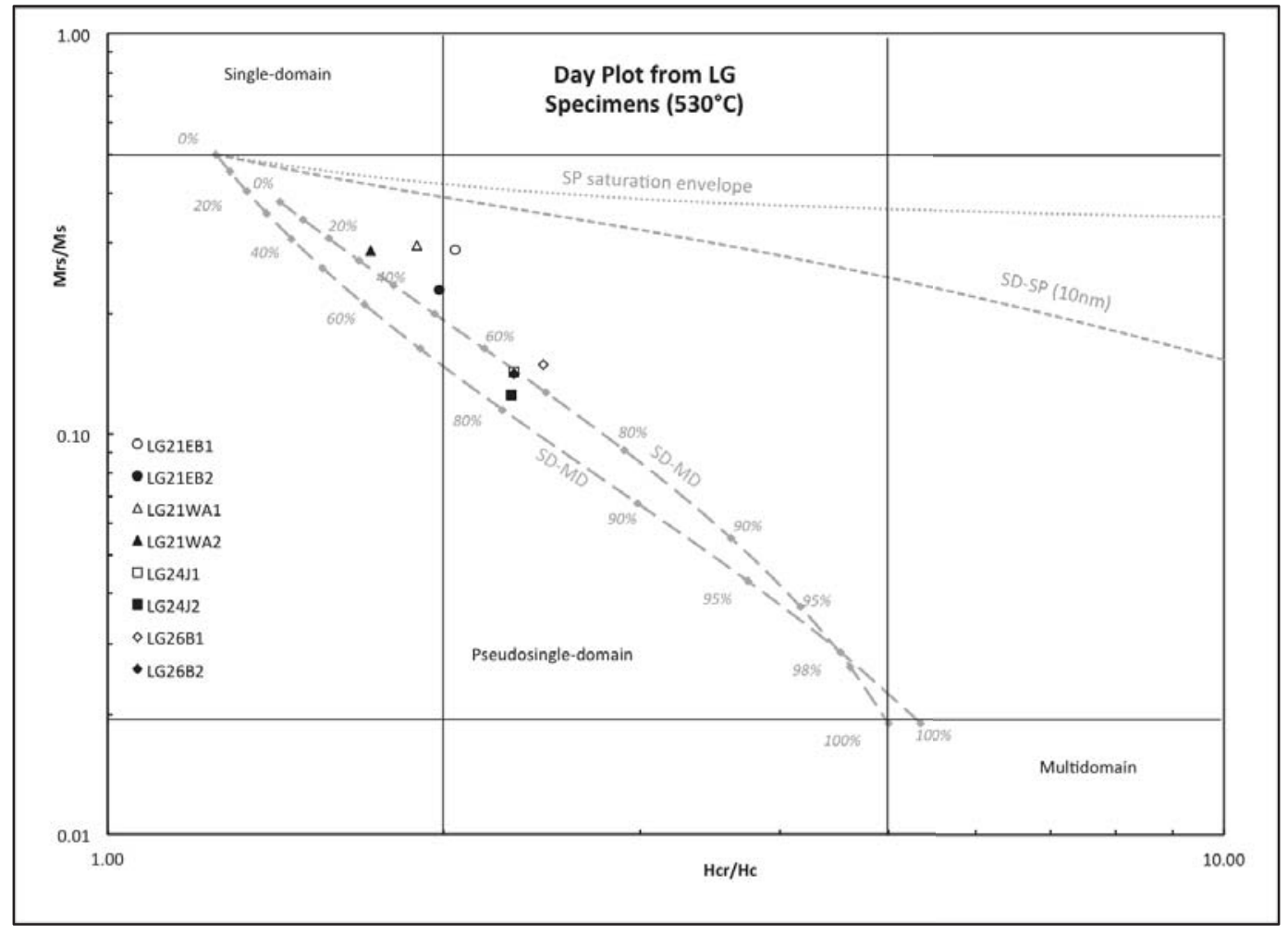


Figure 3.2: Day plot for Lemptégy specimens heated to $530^{\circ} \mathrm{C}$. Empty symbols represent specimens measured before heating. Full symbols represent the same specimens after heating.

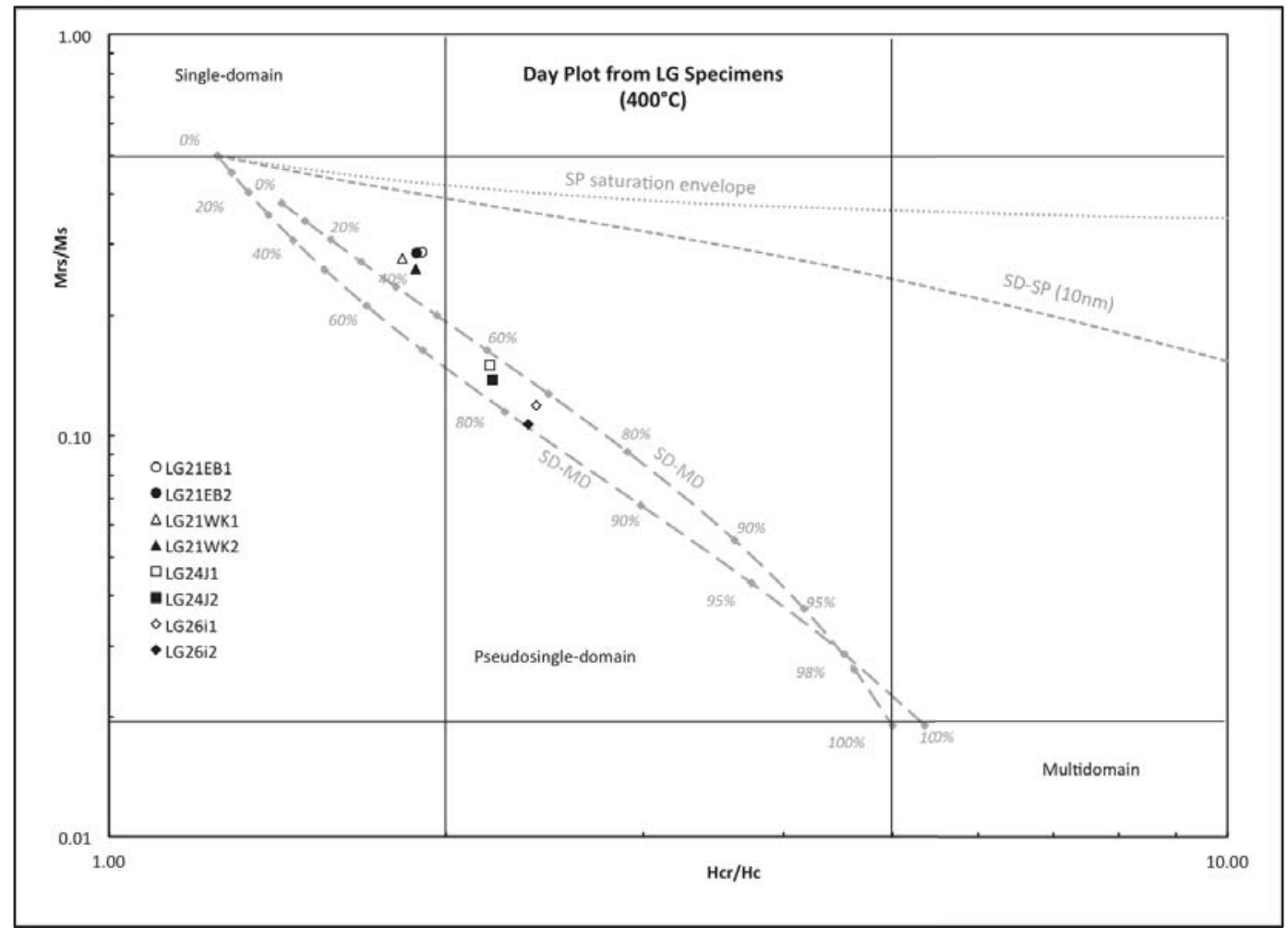

Figure 3.3: Day plot of Lemptégy specimens heated to $400^{\circ} \mathrm{C}$. Empty symbols represent specimens before heating. Full symbols represent the same specimens after heating.

\subsubsection{Temperature Dependence of Magnetic Susceptibility}

The thermomagnetic curves obtained during testing show the change in susceptibility of the specimens in a weak field at a range of temperatures. This can be used to estimate the Curie temperature of the rocks at each site. Hopkinson peaks (the distinctive high point in susceptibility reached just before a sharp decrease), which can be used to determine Curie temperatures, are notably absent from the thermomagnetic curves of specimens from all four sites. As such, the Curie temperatures were estimated using the inflection point method, looking for the steepest slope of the curve representing the decrease in susceptibility due to heating (Fabian et al., 2013). The inflection point of the thermomagnetic curves generally fell slightly before $600^{\circ} \mathrm{C}$, corresponding with the $580^{\circ} \mathrm{C}$ Curie temperature of magnetite. Additionally, the thermomagnetic curves tend to 
show a noticeable peak at around $150^{\circ} \mathrm{C}$, corresponding to the Verwey transition of magnetite (Verwey, 1939).

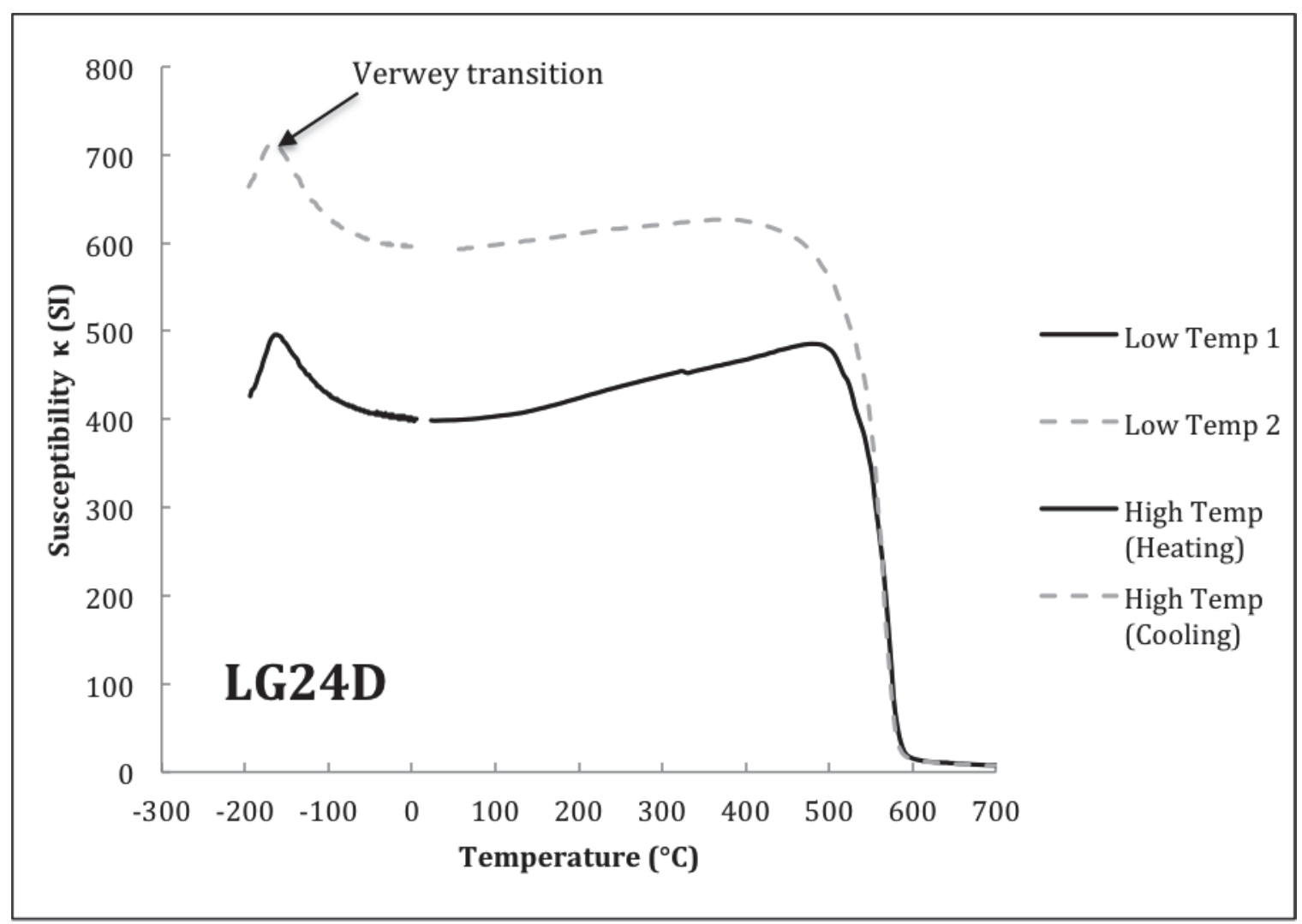

Figure 3.4: Typical thermomagnetic susceptibility curve for Lemptégy samples. Low Temp 1 refers to the first heating from $190^{\circ} \mathrm{C}$ to room temperature. High Temp refers to the heating of the specimen to and cooling from $700^{\circ} \mathrm{C}$. Low Temp 2 refers to the second heating from $190^{\circ} \mathrm{C}$, performed after the high temperature experiment.

A second critical observation is that the thermomagnetic curves of all of the Lemptégy specimens were not reversible, that is, the susceptibility during heating is different from that during cooling. This indicates that some form of mineralogical alteration took place in the specimens due to heating to a high temperature. Since the specimens were heated in an argon environment, the possibility of alteration due to oxidation can be dismissed. This evidence of alteration is the basis for the necessity of using non-heating paleointensity methods to study these specimens.

Experiments involving heating to a lower temperature $\left(580^{\circ} \mathrm{C}\right)$ resulted in a similar irreversibility. Even heating to a lower temperature $\left(400^{\circ} \mathrm{C}\right)$ showed a small but 
noticeable irreversibility. This agrees with the hysteresis heating data indicating that thermal alteration begins taking place in these specimens at low temperatures.

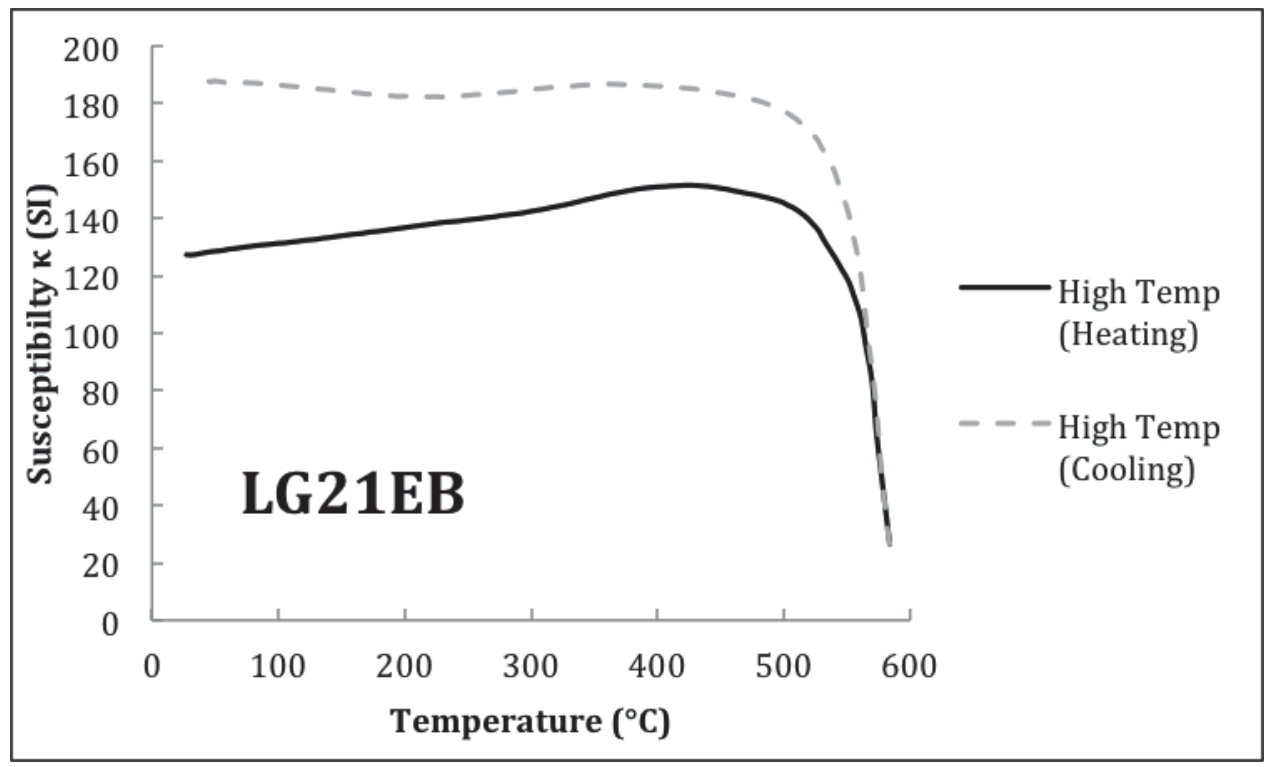

Figure 3.5: Thermomagnetic curve of a Lemptégy specimen heated to $580^{\circ} \mathrm{C}$. The lack of overlapping of the heating and cooling curves demonstrates the heating alteration that takes place.

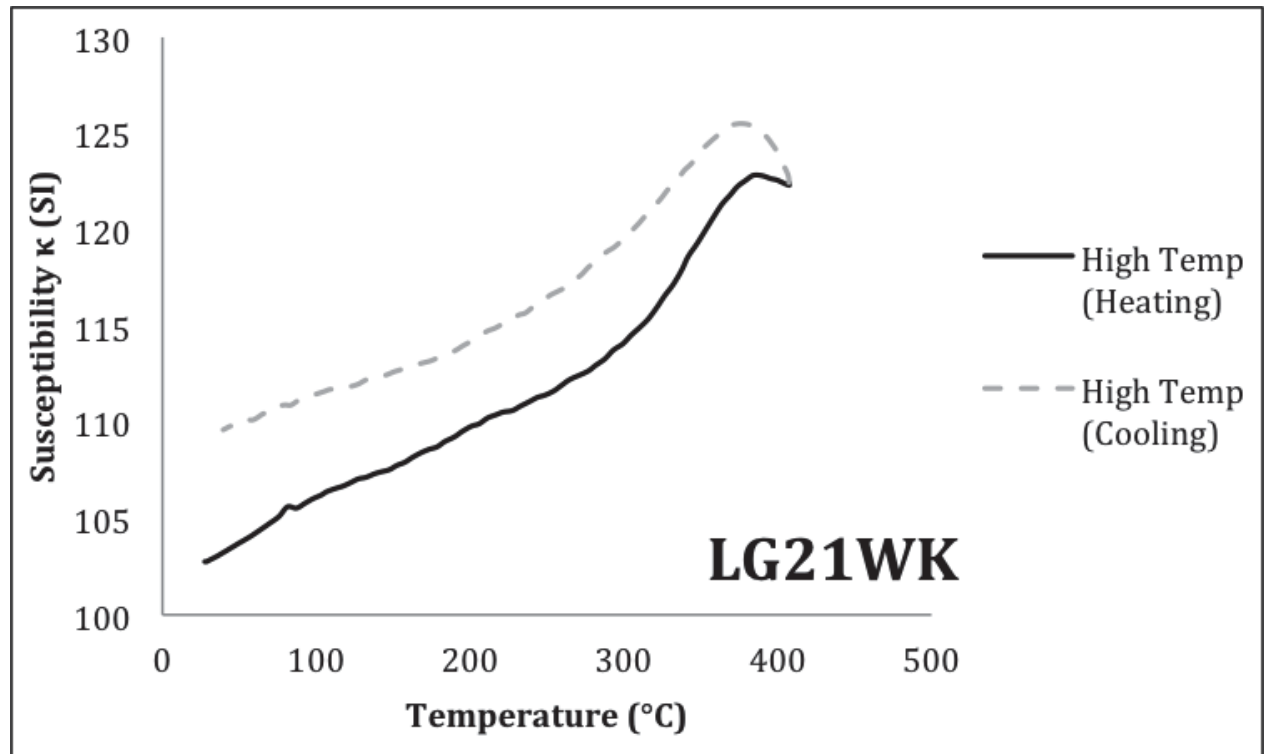

Figure 3.6: Thermomagnetic curve of a Lemptégy specimen heated to $400^{\circ} \mathrm{C}$. The irreversibility of the curve demonstrates that a small amount of heating alteration takes place even at low temperatures. 


\subsection{Paleomagnetism}

All four sites from Lemptégy yielded interpretable results based on thermal and alternating field demagnetization. Both types of demagnetization resulted in clear paleodirections of the sites' remanence. All four sites contained a consistent direction of characteristic, assumed primary, remanence. However, some sites contained a secondary direction of remanence that was removed either through low temperature demagnetization or lower fields of AF demagnetization. The multiple directions of remanence present in the Lemptégy samples can be seen in Figures 3.7 and 3.8.

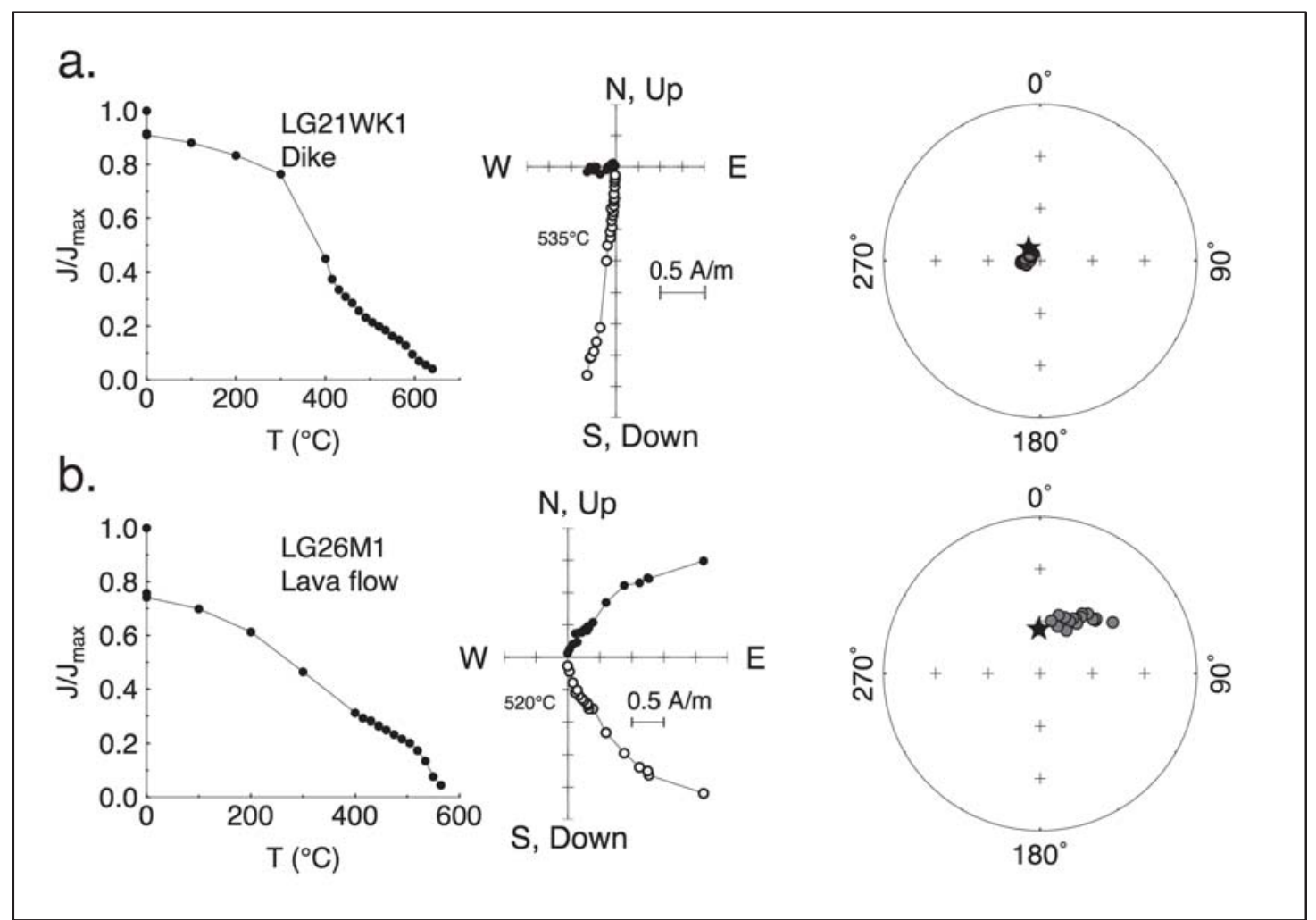

Figure 3.7: Paleomagnetic plots for the thermal demagnetization of two representative Lemptégy specimens, one dike (a) and one lava flow (b). Each set of plots contains a demagnetization curve showing the rate at which the specimen is demagnetized, an orthographic plot showing the change in paleomagnetic declination and inclination during demagnetization, and an equal-area plot showing a stereographic projection of the specimen's paleomagnetic direction (the final direction is marked with a star). The temperature step at which characteristic remanence begins is marked on the orthographic plot. 


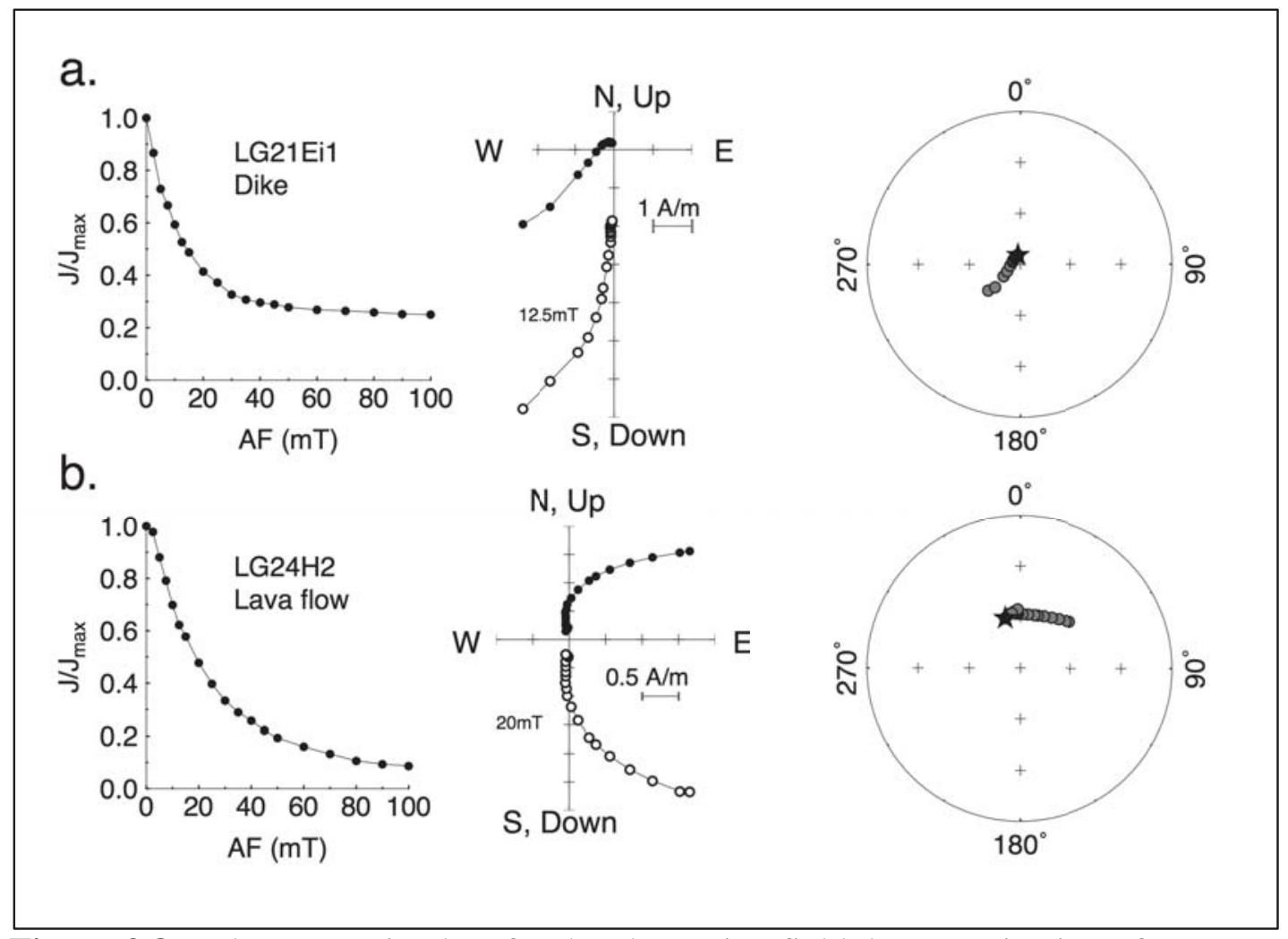

Figure 3.8: Paleomagnetic plots for the alternating field demagnetization of two representative Lemptégy specimens, one dike (a) and one lava flow (b). Each set of plots contains a demagnetization curve showing the rate at which the specimen is demagnetized, an orthographic plot showing the change in paleomagnetic declination and inclination during demagnetization, and an equal-area plot showing a stereographic projection of the specimen's paleomagnetic direction (the final direction is marked with a star). The AF step at which characteristic remanence begins is marked on the orthographic plot.

The results of the demagnetization can be seen in Table 3.1.

Table 3.1: Summary of paleomagnetic data from Lemptégy samples.

\begin{tabular}{llrrrrrrr}
\hline Site & $\boldsymbol{n} / \boldsymbol{N}$ & Declination & Inclination & $\boldsymbol{\alpha}_{\mathbf{9 5}}$ & $\boldsymbol{k}$ & VGP Lat & VGP Long & $\boldsymbol{A}_{\mathbf{9 5}}$ \\
\hline LG21E & $9 / 11$ & 356.2 & 84 & 3.85 & 159.8 & 87.14 & 276.88 & 7.52 \\
LG21W & $8 / 9$ & 338.2 & 85 & 4.44 & 148.3 & 86.33 & 347.73 & 8.72 \\
LG24 & $9 / 10$ & 353.7 & 59.6 & 3.68 & 175.2 & 49.33 & 268.38 & 4.8 \\
LG26 & $10 / 11$ & 4.5 & 60.2 & 4.55 & 219.3 & 50.12 & 255.7 & 6 \\
Mean & $4 / 4$ & 357.3 & 72.3 & 16.6 & & & & \\
\hline
\end{tabular}

$n / N:$ ratio of samples used to samples collected at a site, $R:$ resultant vector length, $\alpha_{95}$ : 95\% confidence interval about estimated vector mean direction, $k$ : best estimate of Fisher precision parameter, VGP Lat: latitude of the virtual geomagnetic pole for the site, VGP Long: (in situ) longitude of the virtual geomagnetic pole for the site, $A_{95}$ : $95 \%$ confidence interval about the site mean VGP direction. 
The directions of the paleomagnetic field are similar to the direction of the present day field. This was expected, as the rocks from Lemptégy are only 32,000 years old. Additionally, some of the measurements are in agreement with previous data collected from the same site (Petronis et al., 2013). The paleomagnetic directions determined from of the four sites can be seen on an equal area diagram in Figure 3.9.

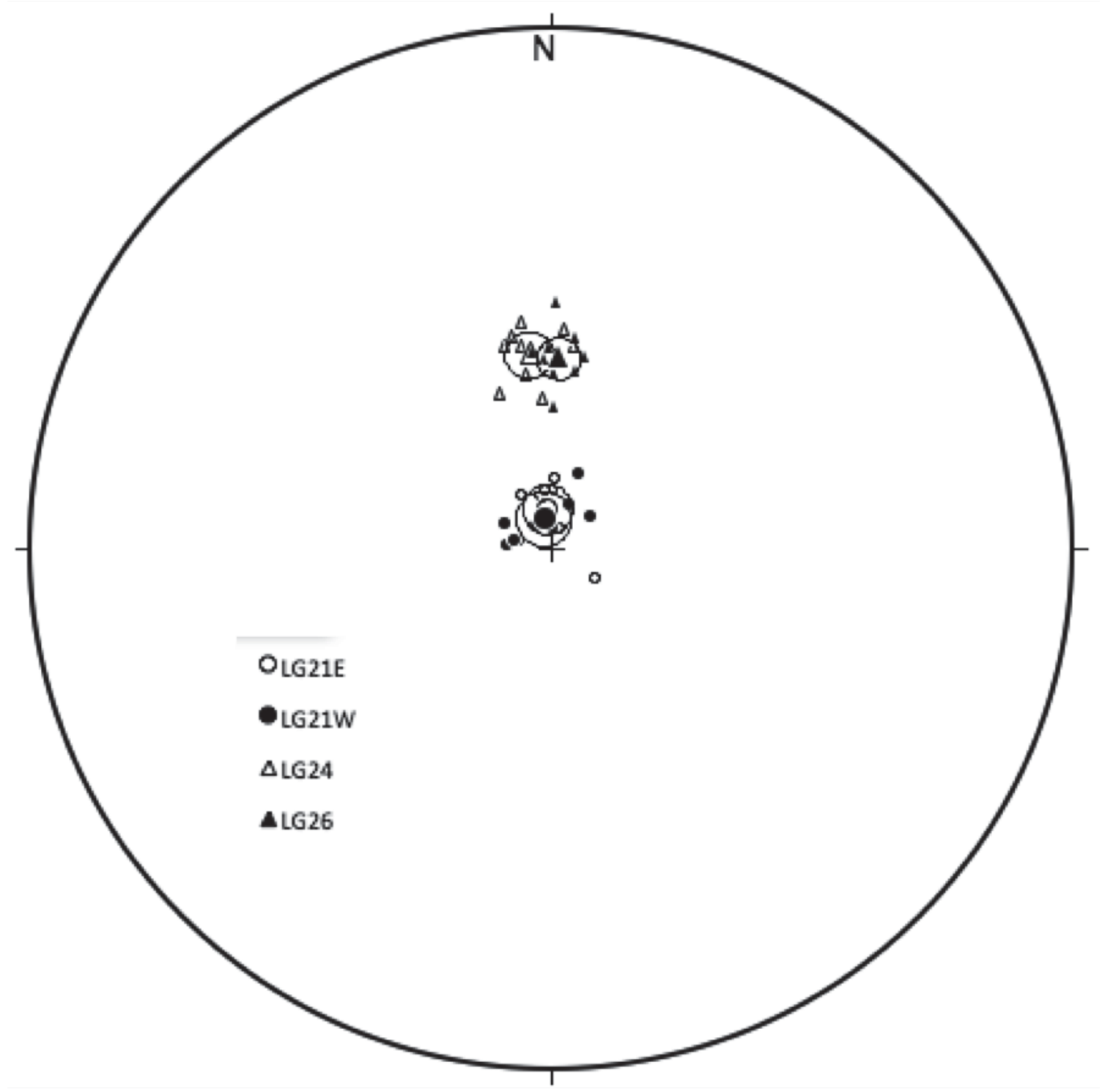

Figure 3.9: Equal area representation of LG sample paleodirections. The large symbols represent the site mean surrounded by the $95 \%$ confidence circle. 
However, although the paleodirections of each site were internally consistent, they were not all in agreement. The directions obtained for the dike sites (LG21E and LG21W) were statistically different from those of the flow sites (LG24 and LG26). As this difference in direction could not be adequately explained by any data collected during this study, these sites were deemed unsuitable for comparison to one other as was the original intention of this study.

In some of the dike specimens, heating $670^{\circ} \mathrm{C}$ was required for complete demagnetization. In some specimens from these same sites, the highest alternating fields of $120 \mathrm{mT}$ were not able to fully demagnetize the specimens. This indicates the presence of hematite within the rocks since hematite requires a high field or temperature to demagnetize (Dunlop and Özdemir, 1997).

\subsection{Paleointensity}

\subsubsection{Lemptégy Specimens}

Paleointensity estimates were obtained for all four Lemptégy sites and can be seen in Table 3.2 below. Estimates were obtained using all methods except for the Preisach method.

Table 3.2: Summary of paleointensity data from Lemptégy samples

\begin{tabular}{llllllll}
\hline Site & $\boldsymbol{n} / \boldsymbol{N}^{*}$ & Pseudo-Thellier & ARM & REM & REMc & REM' & Preisach \\
\hline LG21E & $5 / 5$ & $23.4 \pm 7.03$ & $244 \pm 86.3$ & $820 \pm 388$ & $1460 \pm 1030$ & $300 \pm 199$ & n/a \\
LG21W & $5 / 5$ & $18.5 \pm 6.26$ & $186 \pm 10.9$ & $510 \pm 425$ & $1070 \pm 1120$ & $247 \pm 300$ & n/a \\
LG24 & $5 / 5$ & $30.8 \pm 6.67$ & $198 \pm 21.6$ & $341 \pm 89.8$ & $926 \pm 242$ & $225 \pm 81.8$ & n/a \\
LG26 & $5 / 5$ & $28.7 \pm 1.39$ & $197 \pm 33.6$ & $384 \pm 271$ & $898 \pm 491$ & $302 \pm 283$ & n/a \\
\hline
\end{tabular}

All paleointensity estimates are in $\mu \mathrm{T}$.

$n / N^{*}$ ratio of samples used to samples attempted for a site; $5 / 5$ ratio applies to all methods except Psuedo-Thellier (4/4 for all sites) and Preisach (0/4 for all sites)

While limited data has been collected on the Earth's magnetic field 32,000 years ago, what information is available indicates the paleofield strength was less than the present day value of $47 \mu \mathrm{T}$ (Laj et al. 2004). In this study, however, it is immediately clear that the majority of results obtained are values far higher than any paleointensity that could have existed at any time in the Earth's recent history. When expressed in terms 
of the virtual dipole moment (VDM), the Earth's magnetic field strength was shown not to exceed $14 \cdot 10^{22} \mathrm{Am}^{2}$ (Tarduno and Smirnov, 2004). For the latitude of Lemptégy sites this translates into the field intensity value of $85 \mu \mathrm{T}$.

The Pseudo-Thellier method was the only approach used in this study to produce any reasonable paleointensity estimate for the natural samples. The results for some of the sites are within a standard deviation of the possible known field for the Lemptégy eruption, and the values obtained are certainly low enough to be possible.

The REM methods all produced estimates far too high to be likely. The REM method was only used for comparison, as it was unlikely to work due to the multiple directions of remanence found in the samples. The REM' method, in which the demagnetization curves of NRM and SIRM were compared over a range, rather than a point (as with REMc) produced the lowest paleointensity estimates and standard deviations of the three REM methods.

The ARM method was far more internally consistent than the REM methods, producing much lower variation in result in addition to lower values. This would seem to support the argument that ARM is a better analog for TRM than SIRM, however the values obtained in this method were still far higher than any possible accurate result.

The Preisach method failed to produce any successful result for the natural samples. In this method, the user has a great deal of leeway to select the result based on their interpretation of the best fit of the data. Unfortunately, no result was produced using the FORCintense program that could reasonably be construed as a good fit, therefore no paleointensity values of any kind could be obtained.

A comparison of the values obtained using the different methods is shown in Figure 3.10. 


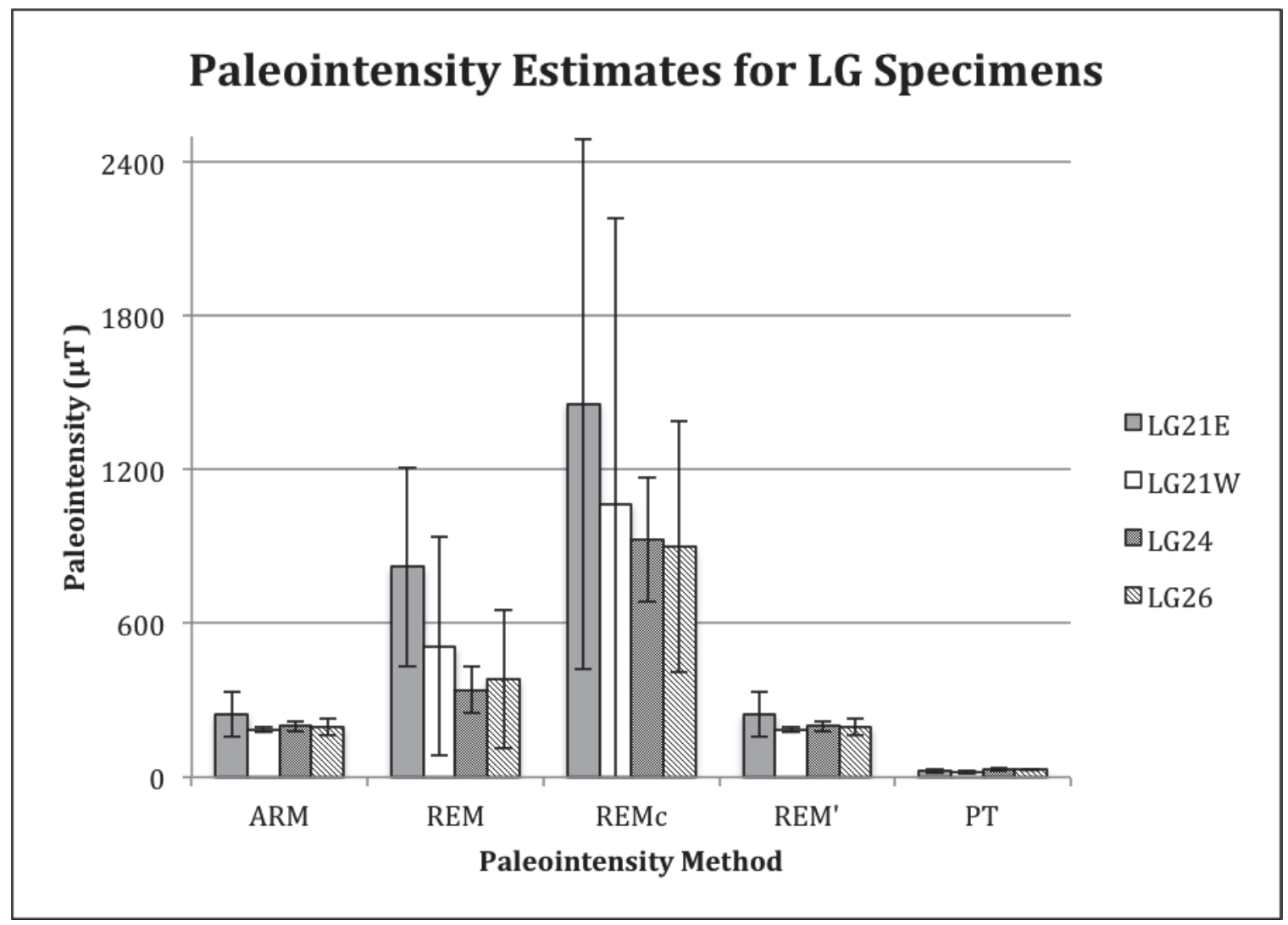

Figure 3.10: Comparison of paleointensity estimates for the Lemptégy specimens. The estimates are grouped by method, with error shown for each specimen type using each method.

\subsubsection{Synthetic Specimens}

Paleointensity estimates were obtained for four of the five synthetic specimen types and can be seen in Table 3.3 below. The multi-domain specimens produced irregular and unstable NRM demagnetization curves and were determined to be unsuitable for any paleointensity experiments. Estimates were obtained using all paleointensity methods attempted. 
Table 3.3: Summary of paleointensity data from synthetic samples

\begin{tabular}{lcllllll}
\hline Specimen & n/N & PT & ARM & REM & REMc & REM' & Preisach \\
\hline S (SD) & $3 / 3$ & $49.3 \pm 0.899$ & $53.0 \pm 3.09$ & $37.5 \pm 5.12$ & $144 \pm 44.0$ & $40.1 \pm 6.61$ & $52.0 \pm 3.74$ \\
$1(0.75)$ & $3 / 3^{*}$ & $48.5 \pm 1.25$ & $48.8 \pm 4.86$ & $32.7 \pm 3.8$ & $145 \pm 56.0$ & $38.9 \pm 5.84$ & $52.5 \pm 5.50$ \\
$2(1.5)$ & $3 / 3^{* *}$ & $51.2 \pm 1.48$ & $57.6 \pm 3.59$ & $33.3 \pm 2.94$ & $175 \pm 56.0$ & $39.5 \pm 9.64$ & $54.5 \pm 5.50$ \\
$3($ Mix $)$ & $3 / 3$ & $48.8 \pm 3.30$ & $56.3 \pm 3.84$ & $39.7 \pm 11.8$ & $218 \pm 85.9$ & $46.2 \pm 8.70$ & $56.7 \pm 4.64$ \\
M (MD) & $0 / 3$ & n/a & n/a & n/a & n/a & n/a & n/a \\
\hline
\end{tabular}

All paleointensity estimates in $\mu \mathrm{T}$.

$n / N$ ratio of samples used to samples attempted per specimen type, * success rate was $3 / 3$ for all methods except REMc, REM', and Preisach (2/3), ** success rate was $3 / 3$ for all methods except Preisach (2/3)

Compared to the natural samples, the synthetic specimens produced more successful results using all methods. As with the natural specimens, the Pseudo-Thellier method produced the most accurate results with the smallest variation. All four specimen types were nearly within a standard deviation away from the expected result of $50 \mu \mathrm{T}$.

The ARM method was nearly as successful, with a tendency to overestimate the paleointensity, while the REM and REM' were less successful with a tendency to underestimate. The REMc method was the only method to produce significantly faulty results, however, this can likely be explained by the fact that the $100 \mathrm{mT}$ AF step was selected for this method to provide contrast with REM. When using this method, the AF step used to obtain a paleointensity estimate is at the discretion of the scientist. As a result, the step chosen can have a dramatic effect on the estimate, depending on the stability of the NRM/SIRM ratio during the course of demagnetization.

Unlike with the natural samples, the Preisach method seemed to produce fairly accurate results in the synthetic specimens. However, like the REMc method, there is a large amount of subjectivity in the data analysis. It is up to the FORCintense program operator to choose the most likely paleointensity estimate based on visual inspection of the program's outputs. Due to this subjectivity, it is possible for the results to be biased by an operator who is inclined to pick values that are close to the expected result. This makes it difficult to have a high level of confidence in the accuracy of the results from this method. 
A comparison of the paleointensity results from the different methods is presented in Figure 3.11.

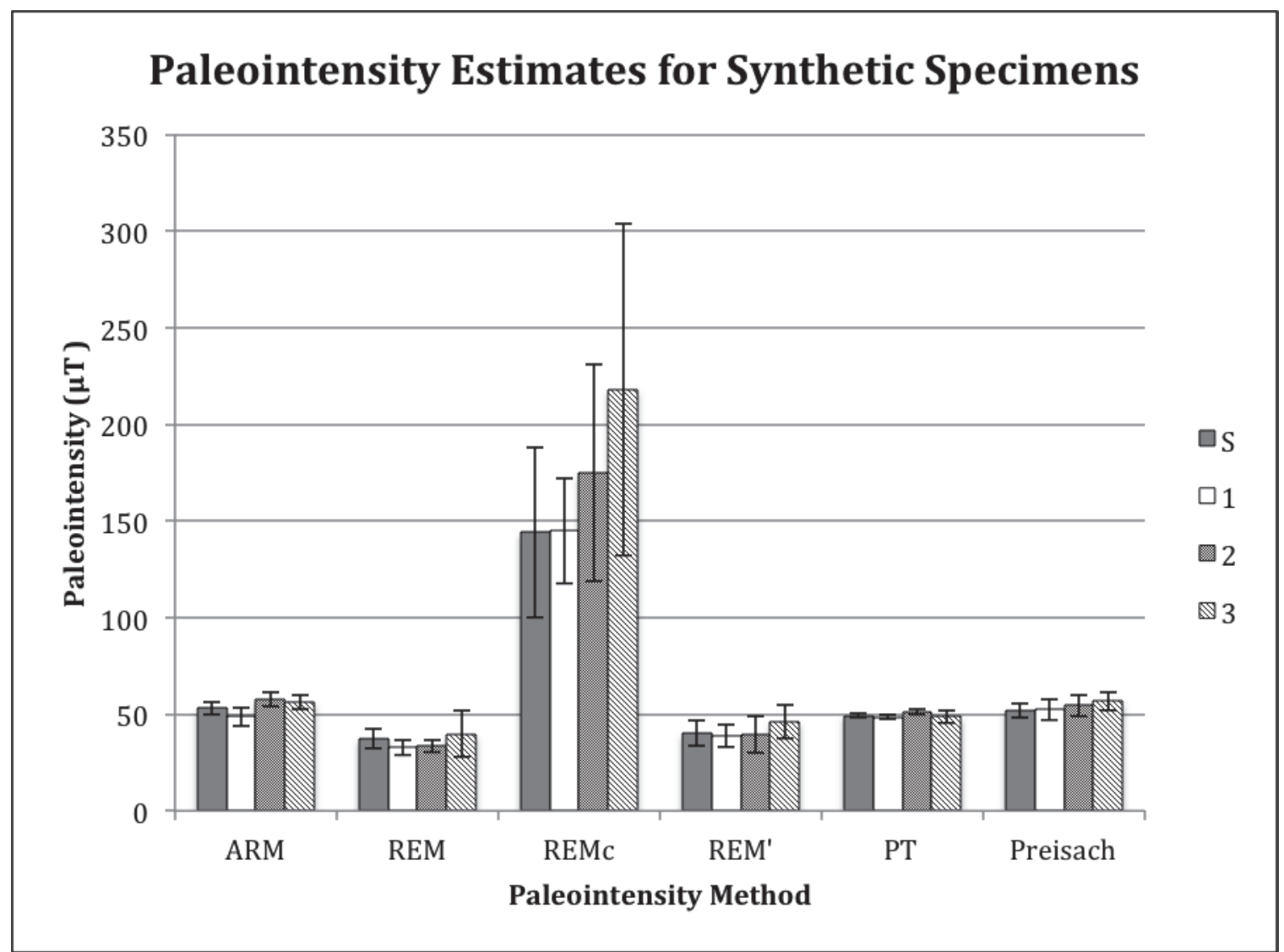

Figure 3.11: Paleointensity estimates for the synthetic specimens. The estimates are grouped by method, with error shown for each specimen type using each method. True paleointensity value is $50 \mu \mathrm{T}$.

\subsection{Microscopy}

Backscatter electron (BSE) images and EDS spectra were obtained for several magnetic grains from a representative sample from each site. The BSE images were be analyzed to determine the abundance, size, shape, and composition of magnetic grains in the dike and flows.

The visible grains in site LG21E ranged from around $1 \mu \mathrm{m}$ to $250 \mu \mathrm{m}$ in diameter, with the majority of the grains smaller than $20 \mu \mathrm{m}$ and very few larger than $50 \mu \mathrm{m}$. The majority of the grains, as seen in Figure 3.12 and 3.13, contained two phases. The light phase of the grain was a Fe-Ti oxide containing almost no $\mathrm{Ti}$ and was interpreted to be 
magnetite. The dark phase (the lamellae) was an Fe-Ti oxide containing a significantly larger portion of $\mathrm{Ti}$ and was interpreted to be ilmenite. This dual phase composition was typical of the majority of the magnetic grains found in the specimens, particularly the large grains.

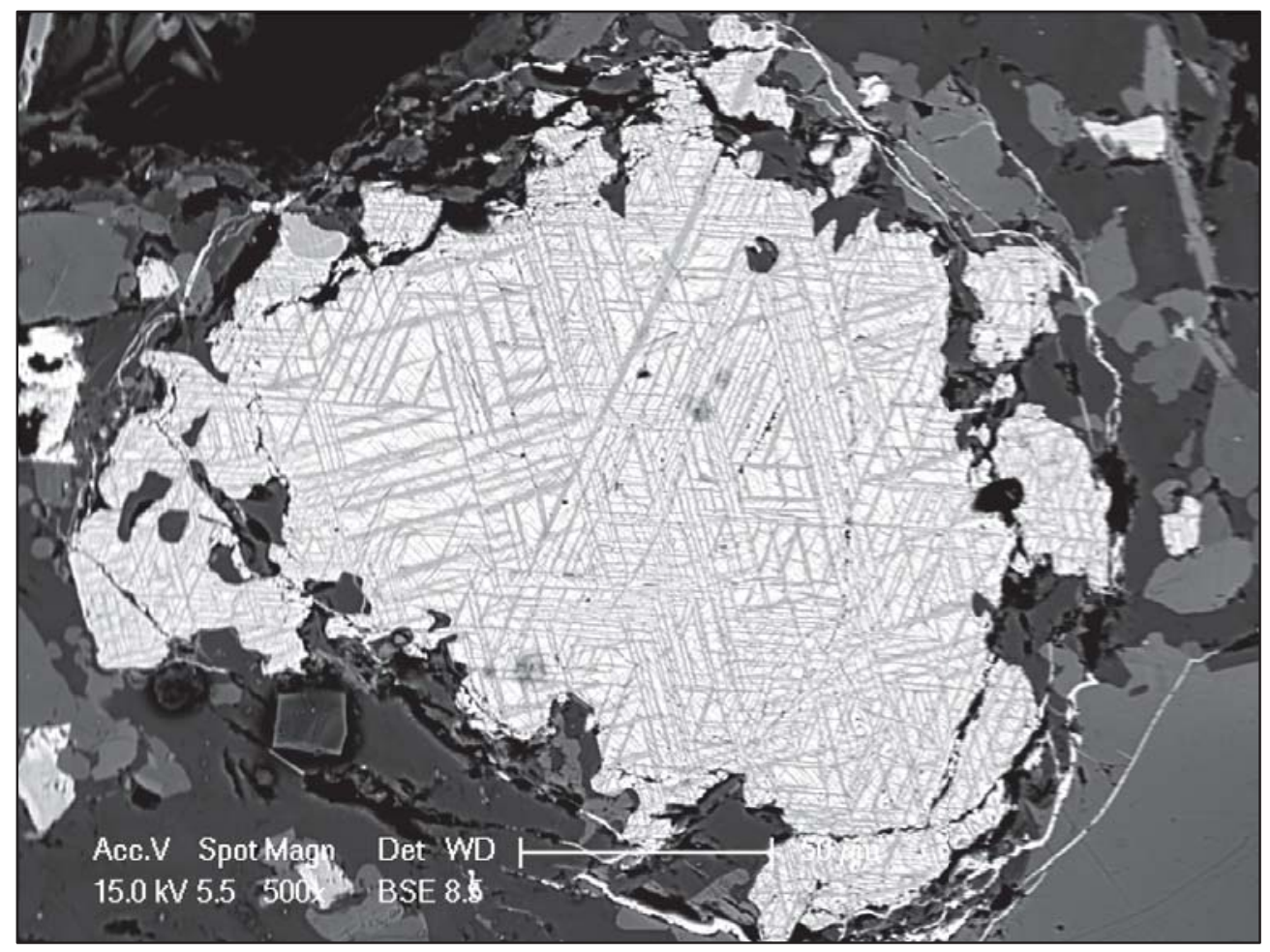

Figure 3.12: A magnetite grain found in LG21E. The grain is approximately 200 microns in diameter. Image taken at 500x. 


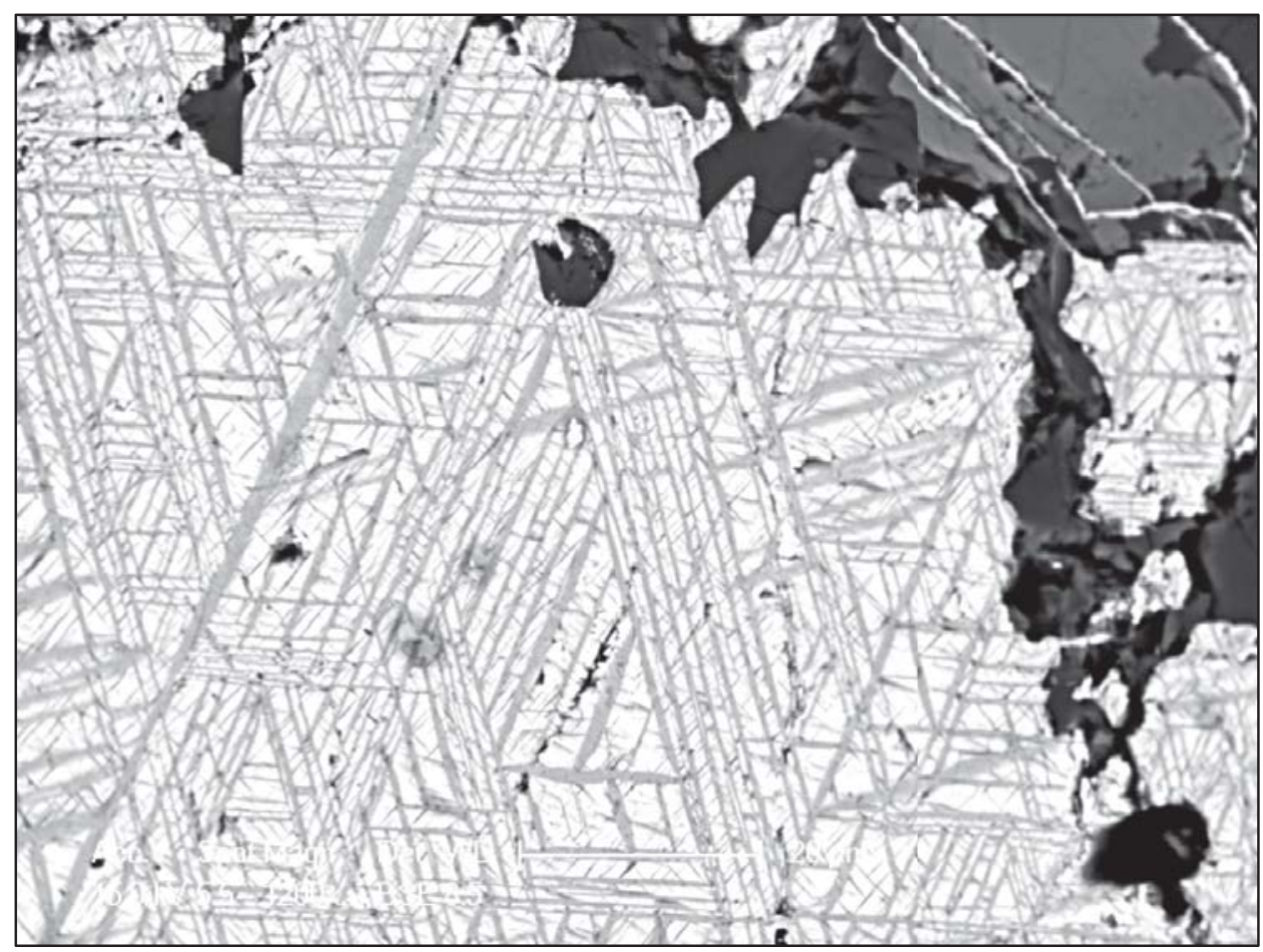

Figure 3.13: An image of the magnetite grain in Figure 3.12 taken at 1200x. Gray exsolution lamellae can clearly be seen.

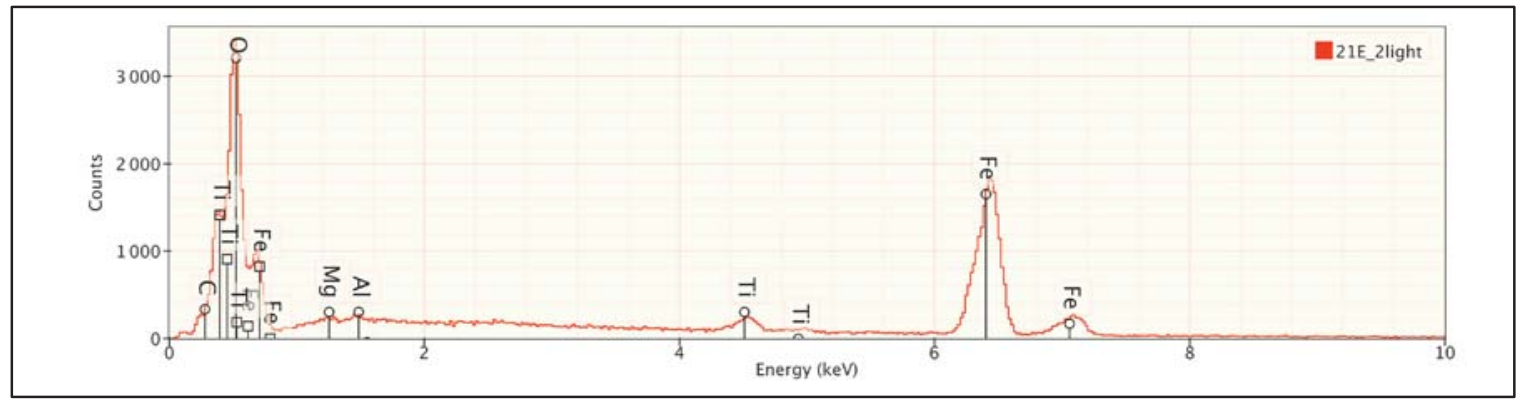

Figure 3.14: An EDS spectrum from the light phase of the specimen in Figure 3.12. This phase was identified as magnetite due to its high Fe content and the near absence of Ti.

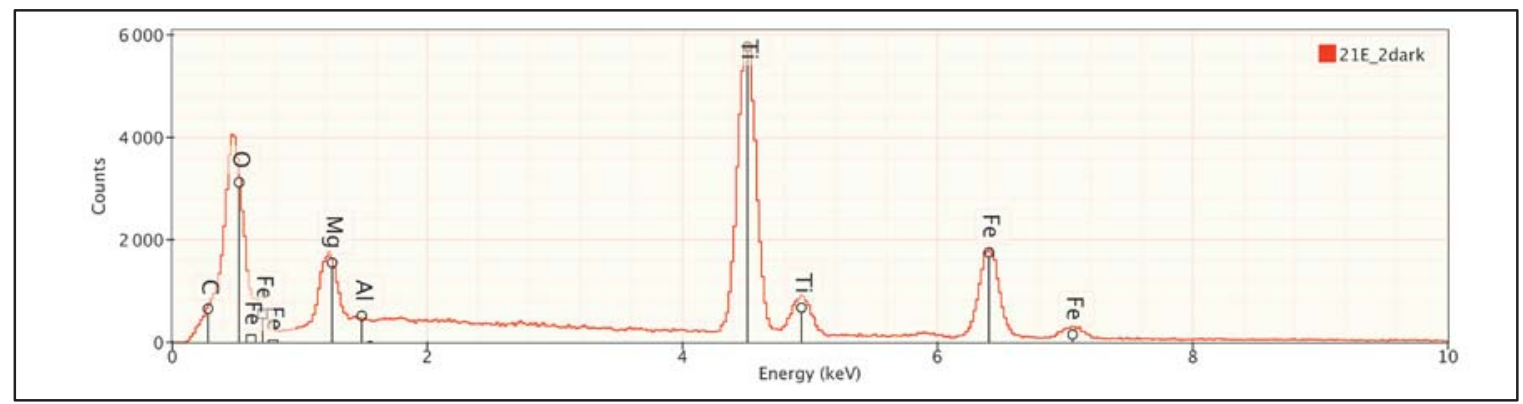

Figure 3.15: An EDS spectrum from the dark phase of the specimen in Figure 3.12. The lamellae were identified as ilmenite due to the higher presence of Ti. 
The abundance and size of the grains found in LG21W were similar to that of LG21E. This is expected since these specimens from the east and west margins of the same dike. However, the grains found in LG21W were far more altered and less geometrically shaped. Though the lamellae were not all of the same style as in LG21E, the dual-phase nature of the grains was still present in LG21W.

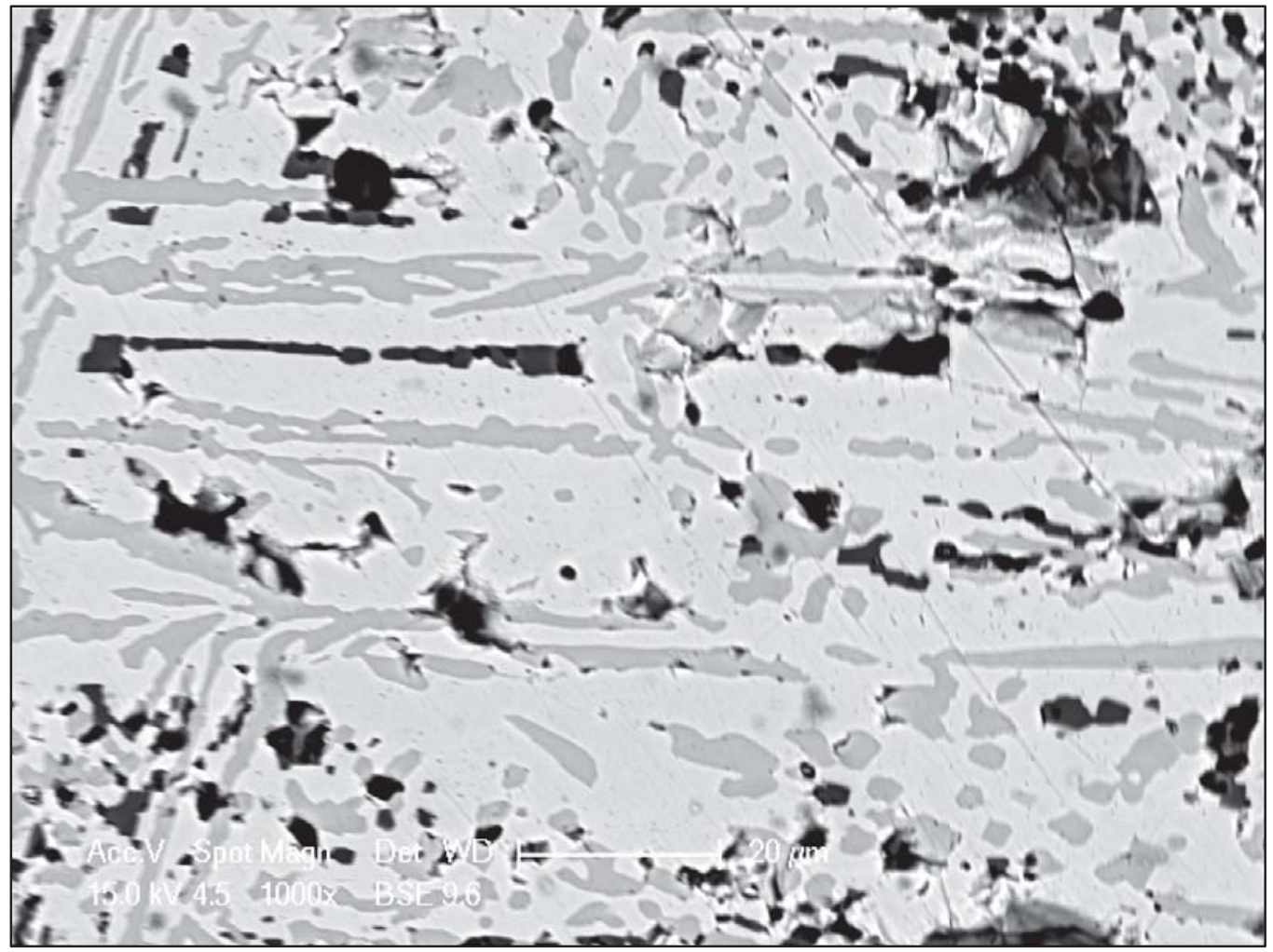

Figure 3.16: Exsolution lamellae in a magnetite grain in LG21W at 1000x magnification. 


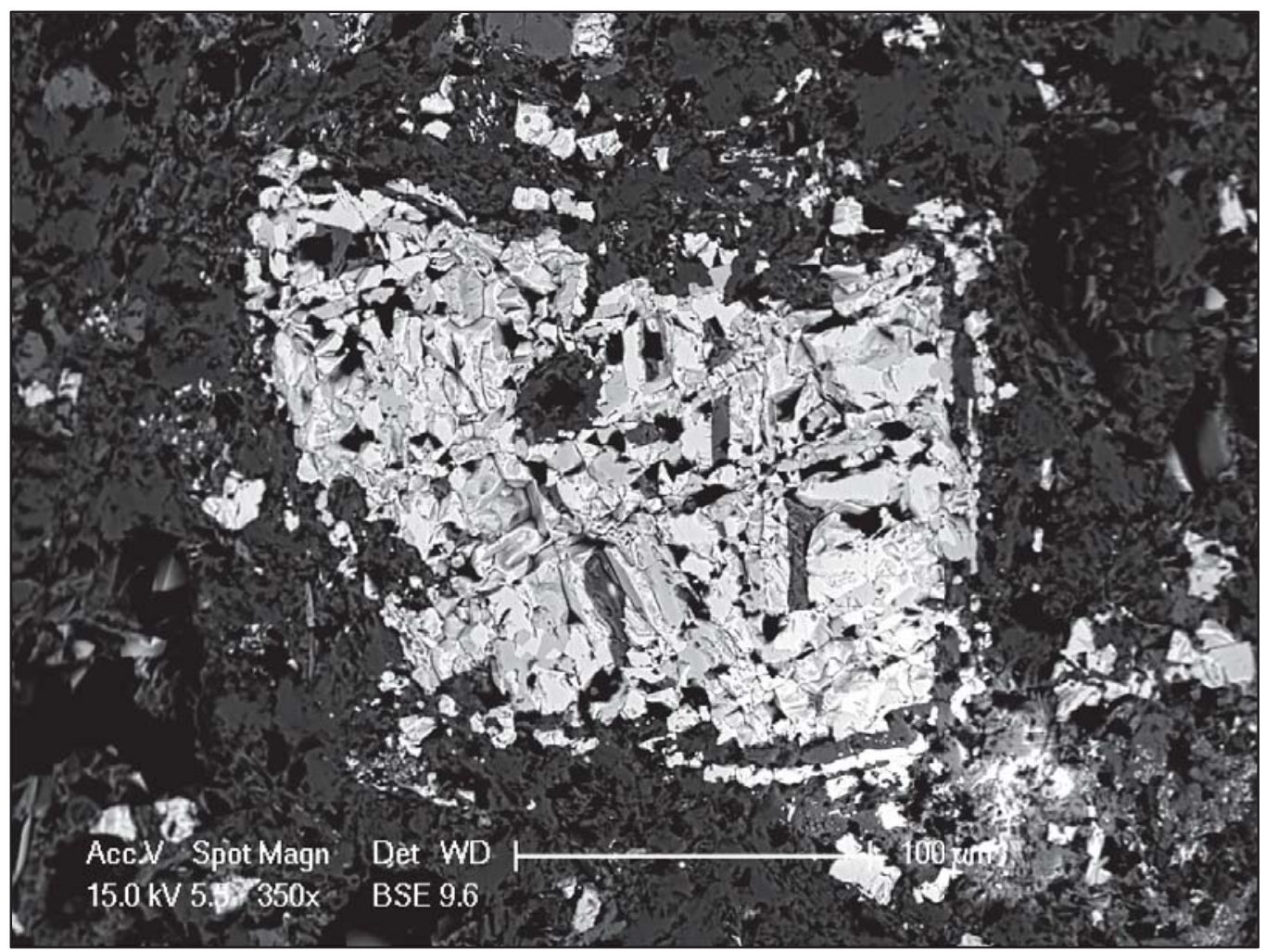

Figure 3.17: Magnetite grain from LG21W shown at 350x. The altered nature of the grain can be easily seen. The grain is approximately $190 \mu \mathrm{m}$ in diameter.

LG24 seemed to contain a lower abundance of visible grains compared to the dike specimens. Grain size ranged from less than $1 \mu \mathrm{m}$ to approximately $200 \mu \mathrm{m}$ in diameter with the majority smaller than $20 \mu \mathrm{m}$. The grains contained the same ilmenite lamellae as the grains in the dike specimens. 


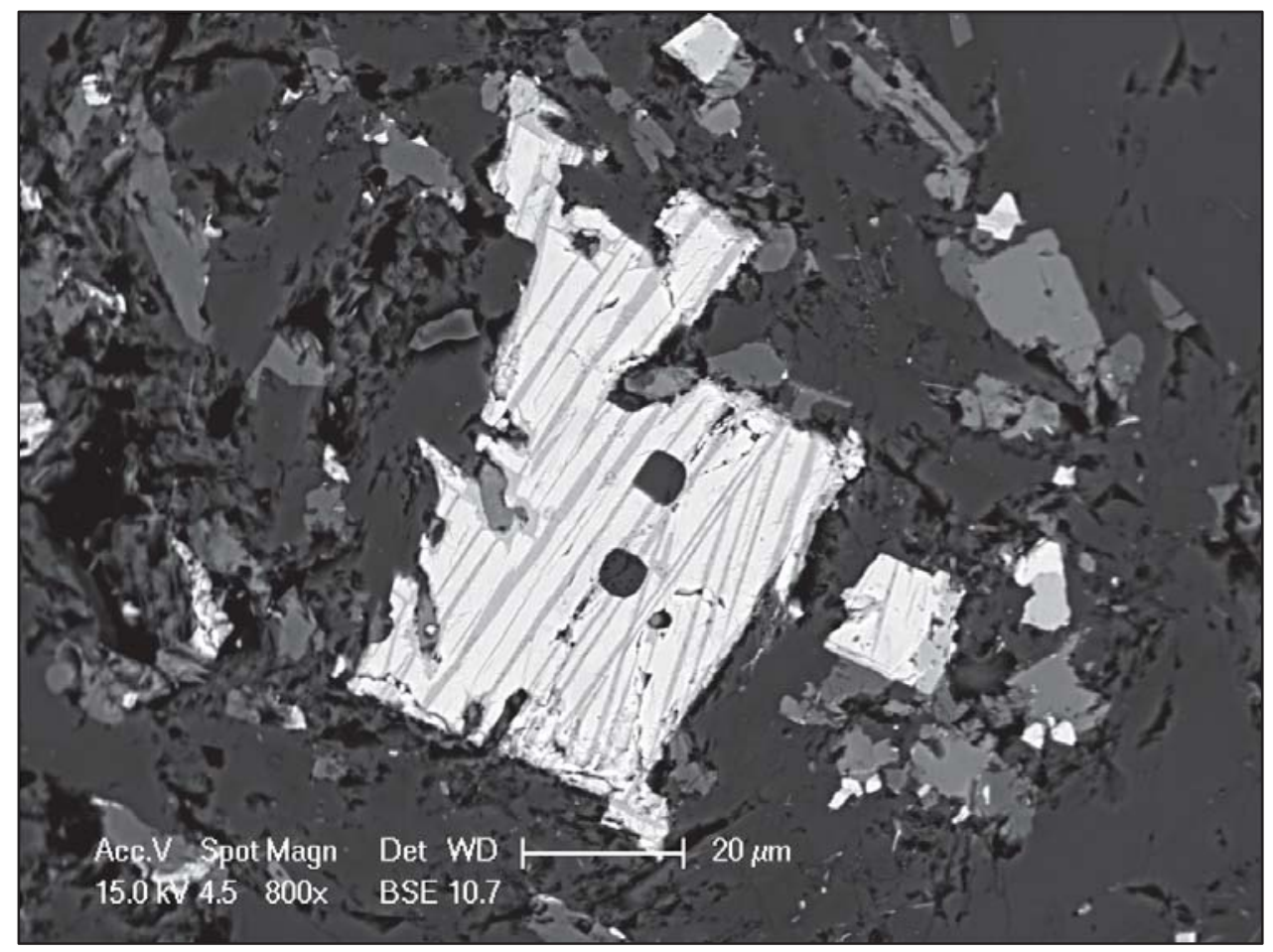

Figure 3.18: Magnetite grain from LG24 shown at 800x. The grain is approximately 60 $\mu \mathrm{m}$ in diameter. The two phases, light (magnetite) with dark lamellae (ilmenite) can be seen.

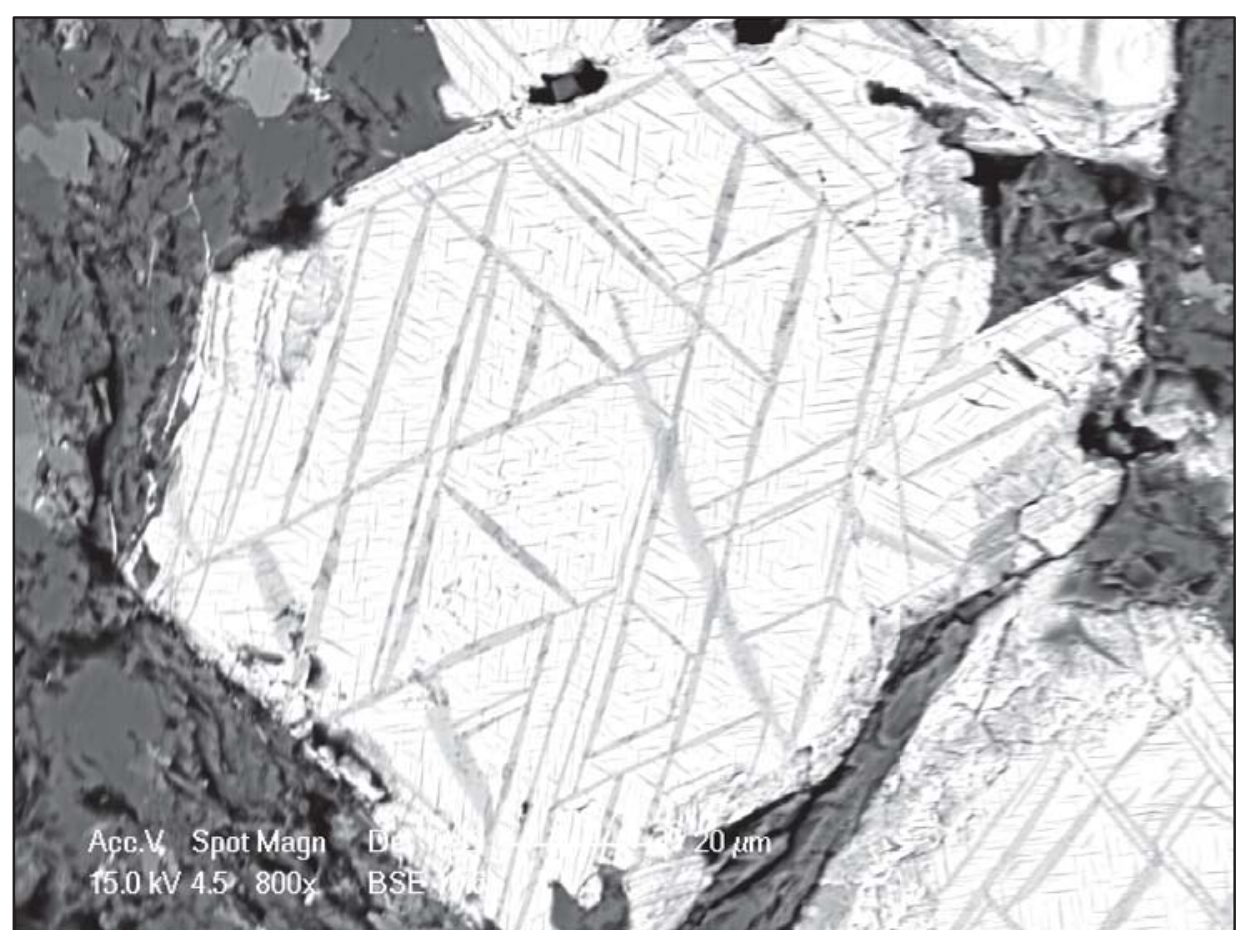

Figure 3.19: Magnetite grain from LG24 shown at 800x. The grain is approximately 100 $\mu \mathrm{m}$ in diameter. 
The grains in LG26 were similar in size and abundance to those in LG24, the other lava flow site. This lava flow site was located physically closer to the dike, which could explain the presence of many grains that were geometrically shaped with lamellae as well as some altered grains similar to those found in LG21W.

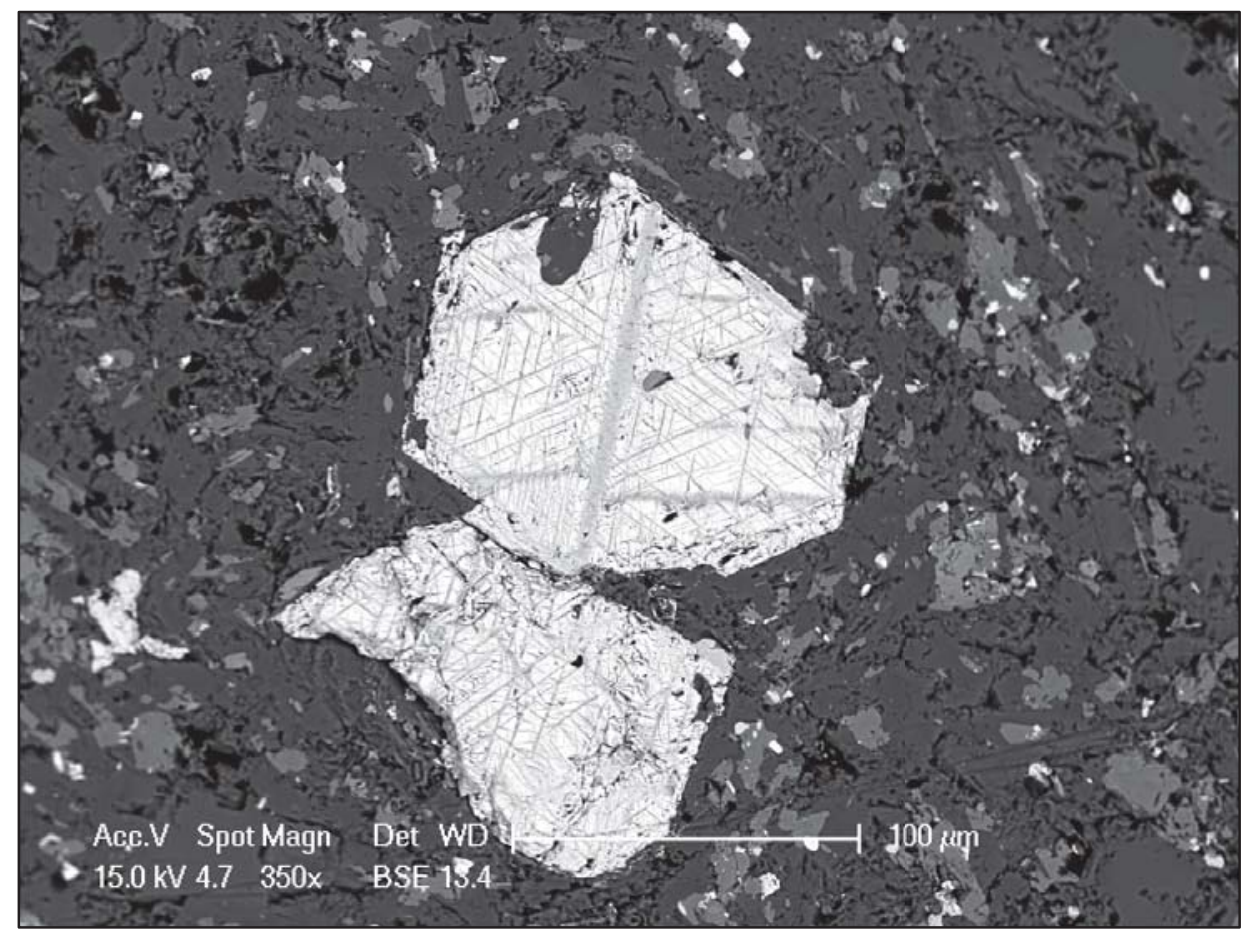

Figure 3.20: Magnetite grain from LG26 shown at 350x. The grain is approximately 120 $\mu \mathrm{m}$ in diameter. The two phases, light (magnetite) with dark lamellae (ilmenite) can be seen. 


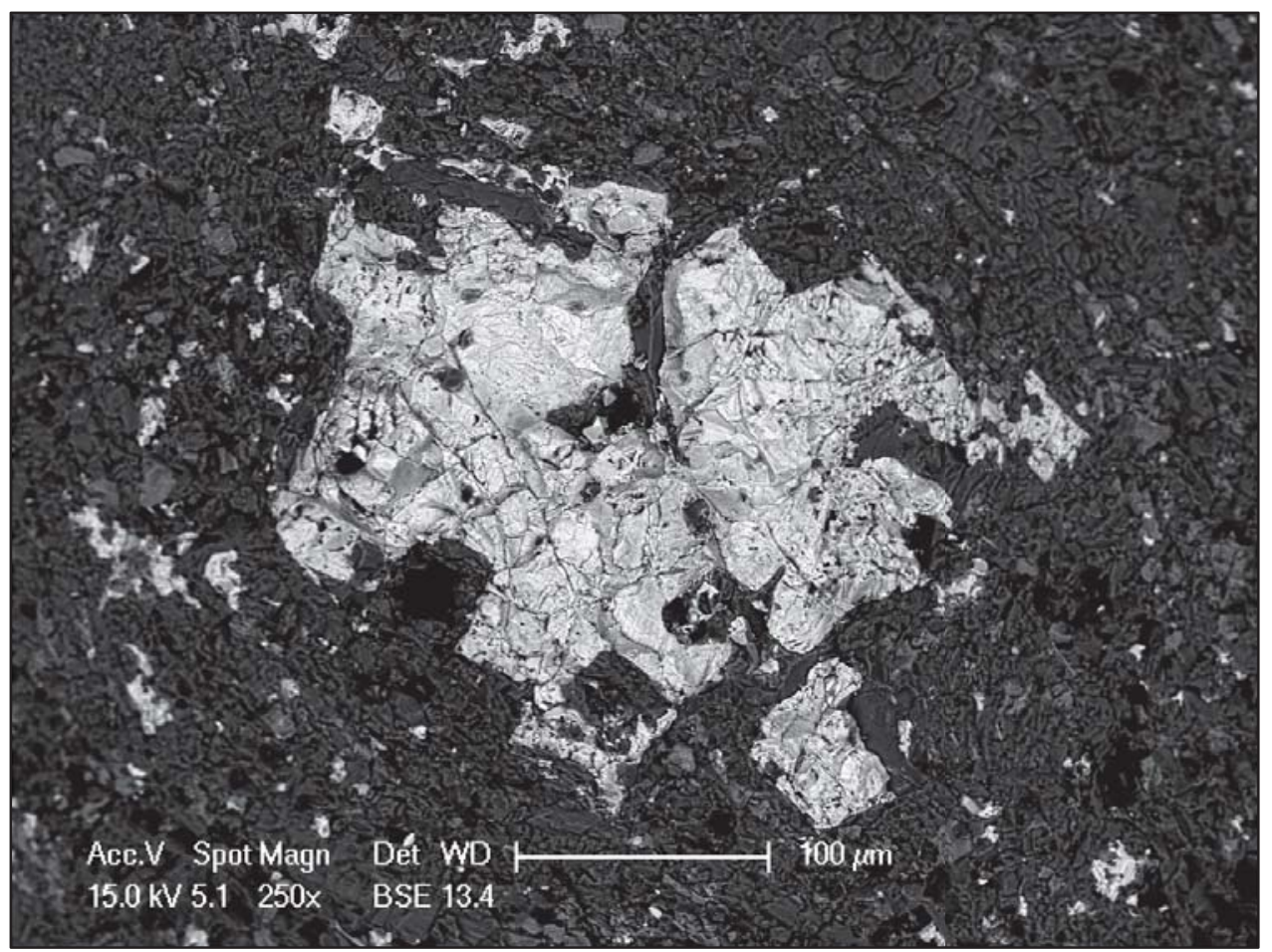

Figure 3.21: Magnetite grain from LG26 shown at 350x. The grain is approximately 250 $\mu \mathrm{m}$ in diameter. The grain is highly altered compared to the grain in Figure 3.20. 


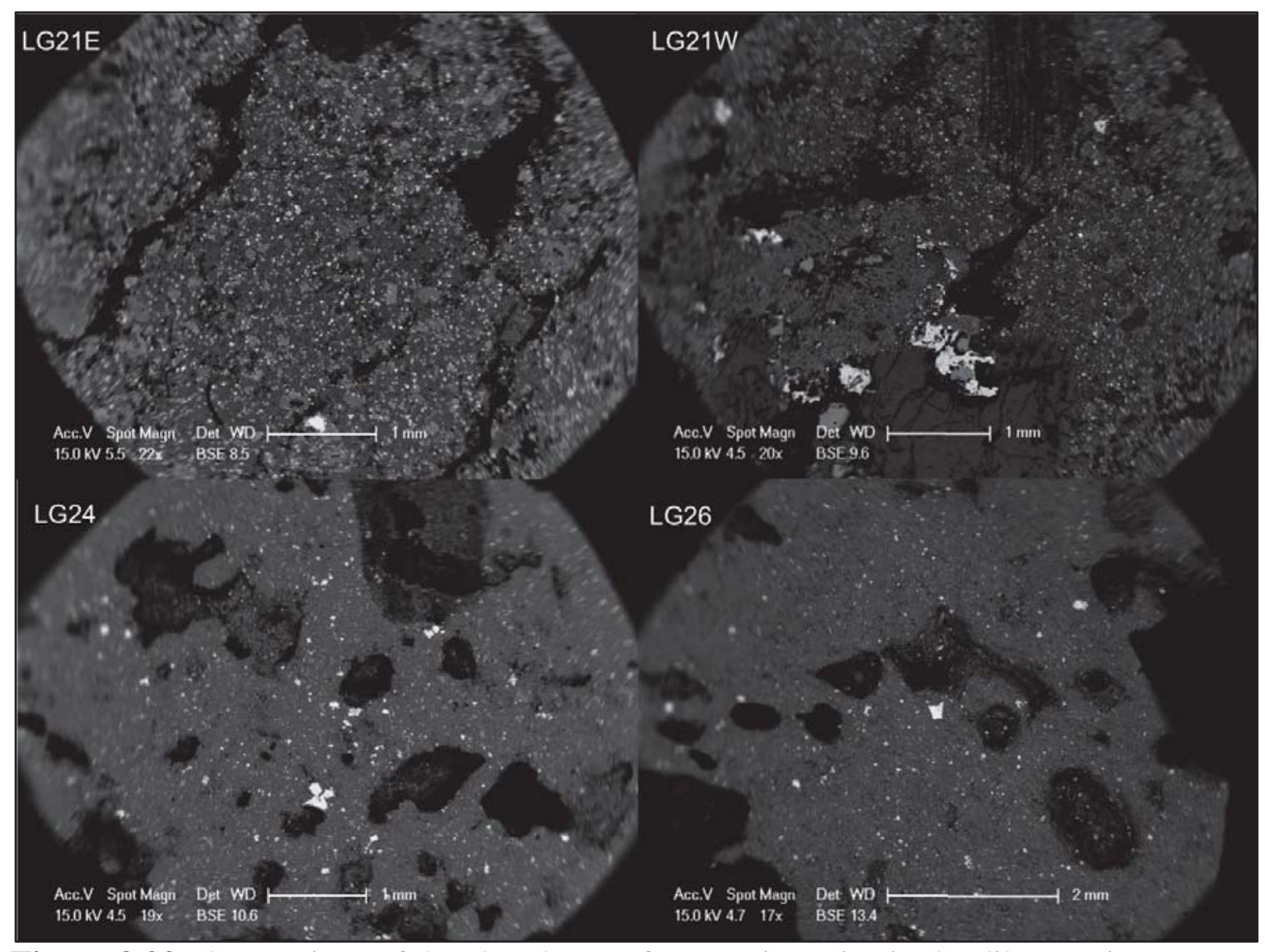

Figure 3.22: Comparison of the abundance of magnetic grains in the dike specimens (upper two images) and the flow specimens (lower two). It is apparent that the abundance of visible grains is higher in the dike.

After heating the specimens to $600^{\circ} \mathrm{C}$, images were taken of the same grains to look for the thermal alteration that appeared to have taken place based on the thermomagnetic and hysteresis data. However, when the before and after heating images were compared, no difference was detected, nor was any difference found in the EDS spectra of the grains after heating (Figures 3.23 and 3.24). 


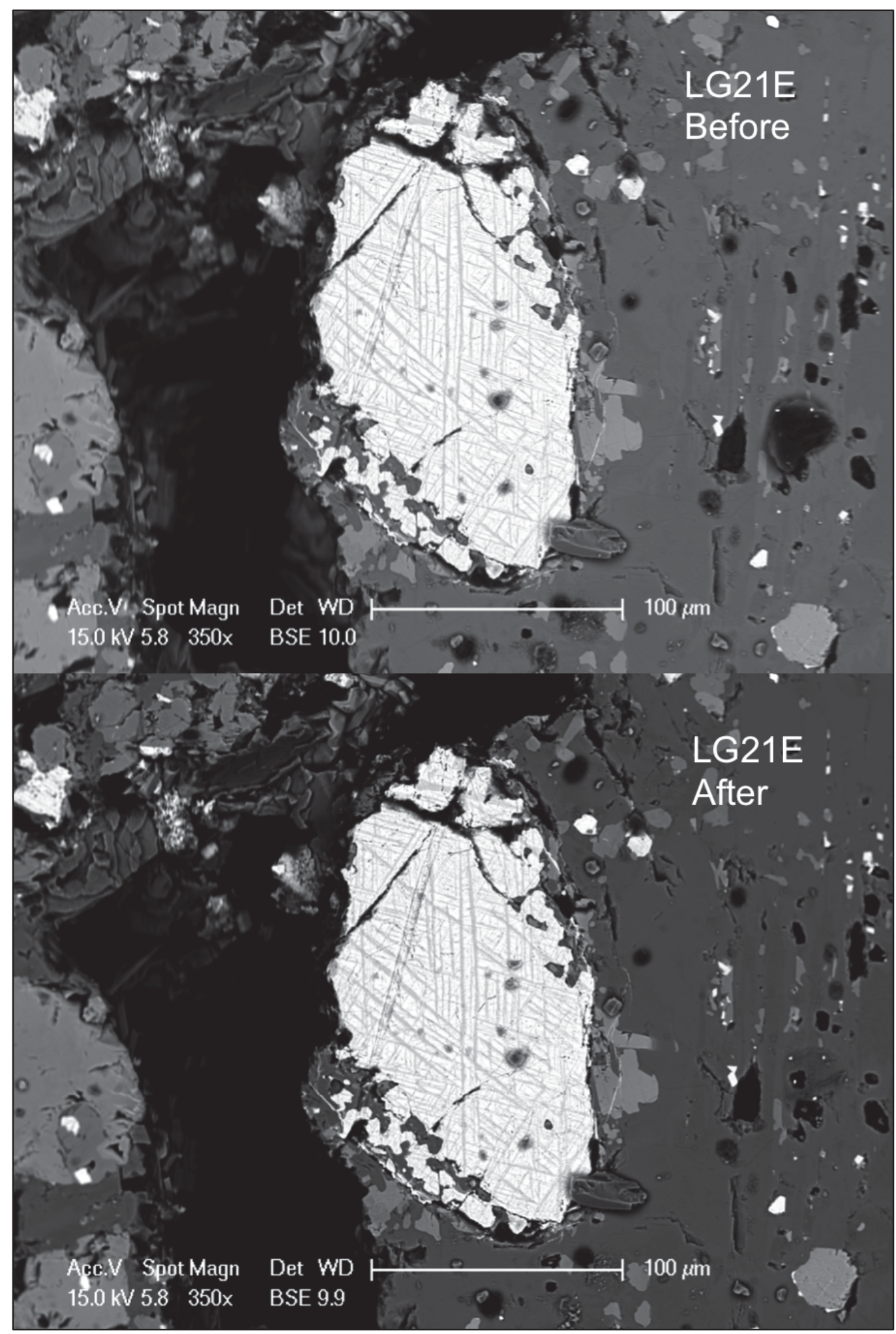

Figure 3.23: Comparison of an LG21E magnetite grain before and after heating to $600^{\circ} \mathrm{C}$. No significant difference between the grains can be seen. Both images were taken at $300 x$. The grain is approximately $100 \mu \mathrm{m}$ in diameter. 


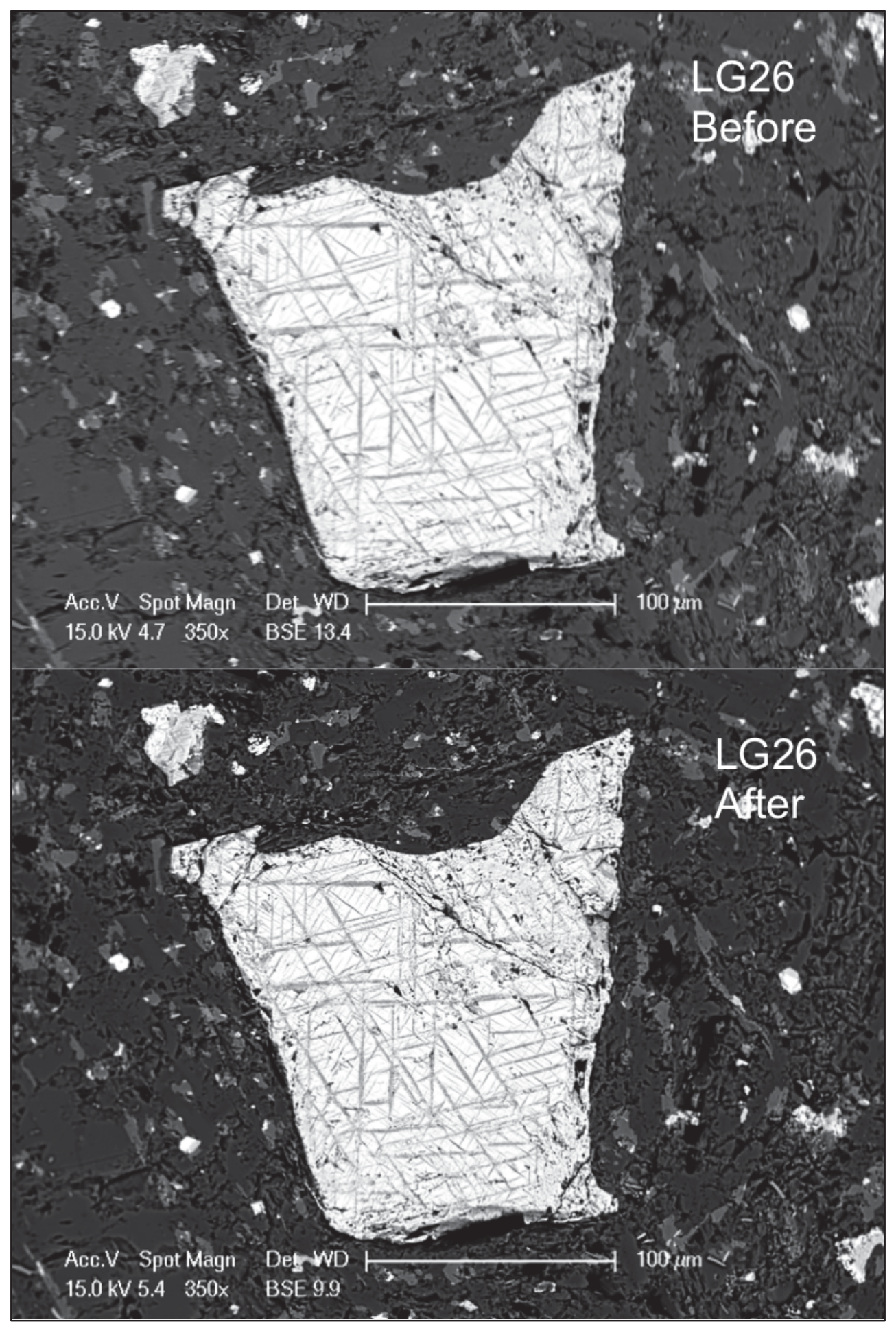

Figure 3.24: Comparison of an LG26 magnetite grain before and after heating to $600^{\circ} \mathrm{C}$. No significant difference between the grains can be seen. Both images were taken at $350 x$. The grain is approximately $120 \mu \mathrm{m}$ in diameter. 


\section{Discussion}

\subsection{Effectiveness of Non-Heating Paleointensity Methods}

The paleointensity methods used in this study had varying levels of success (Figures 3.10 and 3.11). In general, all the methods produced more accurate estimates with significantly lower uncertainty in the synthetic specimens than the natural ones. The failure of most of the methods to produce any realistic result at all (even an inaccurate one) indicates that the non-heating paleointensity methods may not be designed to handle rocks with non-ideal magnetic grains. Since the demagnetization data revealed that the Lemptégy rocks may contain hematite, and the SEM images clearly showed lamellae of higher-Ti magnetic grains, it can be argued that the presence of non-magnetite magnetic grains could have been a cause of the failure of some of the methods.

One concern with the REM trio, which produced the least accurate results in both the synthetic and natural specimens, is that it relies on an empirically derived correction factor to produce paleointensity determinations. This correction factor is usually obtained by measuring historic samples with a known paleointensity. As a result, different authors have determined different correction factors for each method, and no universal correction factor has as of yet been agreed upon. This means that this method may be occasionally useful for confirming the paleointensity determinations from rocks in which it is already known, but may have very limited use in obtaining paleointensity of rocks that have yet to be studied.

The Pseudo-Thellier method was the only method to produce accurate results using both the natural and synthetic specimens. One advantage of this method is that it most closely mirrors the Thellier-Thellier method. While it is not certain that ARM can be considered as a perfect analog for pTRM, it allows for a very similar experimental and interpretation procedure, and produces including an Arai plot. As a result, this method does not rely on any correction factor and should work for a broader range of rock types.

Since the ARM method is so similar in procedure to the Pseudo-Thellier method, it is curious that it produced accurate results only in the synthetic specimens. It would be expected that, like the Pseudo-Thellier method, it would at least produce reasonable results in the natural specimens. It is possible that the demagnetization of ARM was more 
affected by the presence of hematite than the impartation of ARM was, resulting in the two methods having differing levels of success.

As the authors themselves note, the Preisach method is still considered experimental, which could explain the lack of success in the natural specimens. The FORCintense program is not completely intuitive, and with no papers clearly detailing the procedure for using the method, it is difficult to have confidence that the procedure is being carried out in the most advantageous manner. However, the major failing of the Preisach method is the subjectivity of the data analysis. Unlike analyzing an Arai plot, where the best-fit slope necessary to calculate the paleointensity is usually fairly clear cut, the best-fit of the curves in the FORCintense program is extremely open to the user's interpretation. As a result, there is a high possibility of the user biasing the results outputted by the program to better fit what they know or want the paleointensity to be. The clear next upgrade for the Preisach method would be automating the data analysis to allow the program to suggest the best-fit paleointensity based solely on data.

\subsection{Relationship between Cooling Rate, Heating Alteration, and Magnetic Mineralogy and Paleointensity}

The opportunity to use the ESEM to evaluate the Lemptégy samples seemed to be an excellent opportunity to learn about the effect of heating alteration on the magnetic mineralogy in basalts. Based on the data collected on the rocks' hysteresis and thermomagnetic properties, it was clear that some thermal alteration took place in the rocks when heated to temperatures as low as $400^{\circ} \mathrm{C}$. Unfortunately, this heating-induced alteration did not present itself in any visibly measurable way when the rocks were analyzed with the ESEM (Figures 3.23 and 3.24). While attempts to locate the same grains after heating were successful, those grains were visibly unchanged, and their EDS spectra also remained the same as before heating. As a result, attempts to see the effects of heating alteration directly on the magnetite grains were unsuccessful.

ESEM imagery did allow for the evaluation of the effect of cooling rate on the magnetic mineralogy of the natural samples. As can be seen in Figure 3.22, there was a difference in the size and abundance of grains between the dike and flow sites, with the 
dikes appearing to contain a higher abundance of magnetic grains, or at least a larger abundance of grains large enough to be visible within the ESEM's resolution. These observations are consistent with a slower cooling rate of the dike in comparison to that of the lava flow. While the difference in the cooling rate apparently affects the grain size and abundance, it does not seem to affect the extent of sub-solidus oxyexsolution reaction which proceeded to the same stage (Haggerty, 1991) in both dike and lava flow.

Due to the lack of success of most of the paleointensity methods, it is difficult to draw any conclusions from these samples about the effect of cooling rates on paleointensity results. Even setting aside the inaccuracy of the results, there was no consistency between the methods. In the REM and ARM methods, the dike results tended to be systematically higher. In contrast, in the Pseudo-Theller method (the only method to produce reasonable results), the flows produced systematically higher paleointensity values. Within the synthetic specimens, there was similarly no consistent relationship found between grain size and paleointensity estimate, since most of the results fell within each other's margin of error.

\subsection{Cause of Heating Alteration in the Lemptégy Basalts}

There are at least some certainties about the heating alteration observed in the Lemptégy basalts. First, the alteration clearly takes place when the samples are heated. This is strongly evidenced by both the Day plots and the thermomagnetic curves (Figures 3.2 and 3.4). The magnetic behavior of the rocks is markedly different post-heating. Second, the thermomagnetic curves show consistently that the magnetic susceptibility of the rocks increases after heating. This indicates that some new magnetic material forms during the heating process.

There are a number of potential mechanisms of the observed heating-induced alteration. The first mechanism relates to the exsolution lamellae seen in the ESEM images of the samples (Figure 3.13). These lamellae may represent the incomplete oxyexsolution of the magnetite and ilmenite during cooling. It is possible that the reheating of the rocks to a high temperature allowed for the completion of the oxyexsolution process, resulting in the changes to the samples' magnetic mineralogy. 
Unfortunately, this additional unmixing did not present in any visible way during the ESEM analysis. Additionally, the low temperature at which the heating alteration begins to take place (about $400{ }^{\circ} \mathrm{C}$ ) seems inconsistent with this type of alteration that requires high diffusion rates for iron and titanium.

A second potential mechanism is the formation of new magnetic minerals from clays in the rock. This would lead to an increased abundance of magnetic minerals, which would change the magnetic behavior of the basalts. However, comparison of the pre- and post-heating ESEM images did not reveal any obvious difference in abundance of magnetic materials (Figures 3.22, 3.23, and 3.24).

A third possibility is the reduction of hematite back into magnetite in the argon atmosphere in which the thermomagnetic curves were measured. This change in magnetic material would also explain the change in behavior of the rocks. However, this type of change in magnetic composition would likely present more obviously in the thermomagnetic data. The fact that the Curie point of the specimens did not change during the thermomagnetic measurements (despite the change in susceptibility) makes this possibility less likely.

Out of these potential causes of heating alteration, the formation of new magnetic minerals from clays in the basalt is the most likely. It is possible that the new magnetic grains have very small grain-sizes (possibly tens of $\mathrm{nm}$ ). Such small grains would significantly change the magnetic properties of the rocks, without being detectable during the ESEM analysis. However, given only the evidence obtained in this study, it is impossible to determine the exact mechanism of the heating alteration in the Lemptégy basalts with certainty. Additional rock magnetic and microscopy experiments are needed.

\section{$\underline{\text { 5. Conclusions }}$}

Non-heating paleointensity methods are an important tool for broadening the range of specimens that are available for learning about the Earth's paleofield. A reliable non-heating method would allow for the study of many samples that are unfit for the Thellier-Thellier and other common methods due to thermal alteration. While these methods can sometimes be used effectively as supplements to heating-based methods, 
unfortunately, most of these methods have yet to prove reliable enough to use alone on rocks with an unknown field.

In this study, only the Pseudo-Thellier method demonstrated an ability to obtain seemingly accurate paleointensity estimates for both synthetic and natural specimens. The rest of the methods failed to produce reasonable estimates for one or both types. This may be due to the need for a correction factor, the effect of secondary hematite on the different re- and demagnetization methods, and the subjectivity of the analysis aspect of the methods.

A better understanding of the reasons for and effects on magnetic mineralogy of thermal alteration in basalts would provide a knowledge base for creating better nonheating paleointensity methods. This study was unable to reach any definitive conclusions on this topic, but further detailed studies of magnetic mineralogy of basalts before and after heating could better explain the changes that take place when heated and the effects these changes have on paleointensity tests.

If further study leads to the creation of more reliable paleointensity methods that work on a wider variety of rock types, it will greatly increase the data available to scientists studying the Earth's magnetic field. This in turn will allow greater insight into the Earth's formation and the history of the geodynamo. 


\section{References}

Acton, G., Yin, Q.-Z., Verosub, K. L., Jovane, L., Roth, A., Jacobsen, B., and Ebel, D. S., 2007, Micromagnetic coercivity distributions and interactions in chondrules with implications for paleointensities of the early solar system: Journal of Geophysical Research, v. 112.

Boivin, P., Besson, J. C., Briot, D., Camus, G., de Goër de Hervé, A., Gourgaud, A., Morel, J. M., Vernet, G., and Vincent, P. M., 2009, Volcanologie de la Chaîne des Puys Massif Central Français.

Boivin, P., Besson, J. C., Briot, D., Gourgaud, A., Labazuy, P., de Larouzière, F. D., Livet, M., Mergoil, J., Miallier, D., Morel, J. M., Vernet, G., and Vincent, P., 2004, Volcanologie de la Chaîne des Puys, Parc Naturel Régional de la Chaîne des Puys Ed., 78 p.:

Butler, R. F., 1992, Paleomagnetism: Magnetic Domains to Geologic Terranes, Blackwell Scientific Publications, 319 p.:

Coe, R. S., and Gromme, C. S., 1973, A Comparison of Three Methods of Determining Geomagnetic Paleointensities: Geomag. Geoelectr., v. 25, p. 415-435.

Day, R., Fuller, M., and Schmidt, V. A., 1977, Hysteresis properties of titanomagnetites: grain-size and compositional dependence: Physics of the Earth and Planetary Interiors, v. 13, p. 260-267.

De Goër de Hervé, A., Camus, G., Lavina, P., and Montel, J. L., 1999, Lemptégy: Volcan à ciel ouvert pour comprendre la Chaîne des Puys: S.A.R.L. Volcano de Lemptégy.

de Groot, L. V., Dekkers, M. J., Visscher, M., and ter Maat, G. W., 2014, Magnetic properties and paleointensities as function of depth in a Hawaiian lava flow: Geochemistry Geophysics Geosystems, v. 15, p. 1096-1112.

de Ramond, P., 1815, Les Monts dômes: Memoirs Academy of Science Inst., p. 1-138. Dekkers, M. J., and Böhnel, H. N., 2006, Reliable absolute palaeointensities independent of magnetic domain state: Earth and Planetary Science Letters, v. 248, p. $508-517$. 
Delcamp, A., van Wyk de Vries, B., and Matthieu, K., 2013, Endogeneous and exogenous growth of Lemptégy monogenetic volcano, Chaîne des Puys, France.: Geosphere (submitted).

Dunlop, D. J., 2002, Theory and application of the Day plot (Mrs/Ms versus Hcr/Hc)

1. Theoretical curves and tests using titanomagnetite data: Journal of Geophysical Research, v. 107.

-, 2011, Physical basis of the Thellier-Thellier and related paleointensity methods: Physics of the Earth and Planetary Interiors, v. 187, p. 118-138.

Dunlop, D. J., and Özdemir, Ö., 1997, Rock Magnetism: Fundamentals and frontiers, Cambridge University Press, 595 p.:

Fabian, K., Shcherbakov, V. P., and McEnroe, S. A., 2013, Measuring the Curie temperature: Geochemistry Geophysics Geosystems, v. 14, no. 4, p. 947-961.

Gattacceca, J., and Rochette, P., 2004, Toward a robust normalized magnetic paleointensity method applied to meteorites: Earth and Planetary Science Letters, v. 227, p. 377-393.

Graham, C. D., 2000, High-Sensitivity Magnetization Measurements: J. Mater. Sci. Technol., v. 16, p. 97-101.

Haggerty, S. E., 1991, Oxide textures; a mini-atlas: Reviews in Mineralogy and Geochemistry, v. 25, p. 129-219.

Harrison, R. J., and Feinberg, J. M., 2008, FORCinel: An improved algorithm for calculating first order reversal curve distributions using locally weighted regression smoothing: Geochemistry Geophysics Geosystems, v. 9.

Hoffman, K. A., Constantine, V. L., and Morse, D. L., 1989, Determination of absolute paleointensity using a multi-specimen procedure: Nature, v. 339, p. 295-297. Kletetschka, G., Kohout, T., and Wasilewski, P. J., 2003, Magnetic remanence in the Murchison meteorite: Meteorics \& Planetary Science, v. 38, no. 3, p. 399-405.

Lappe, S.-C. L. L., Feinberg, J. M., Muxworthy, A. R., and Harrison, R. J., 2013, Comparison and calibration of nonheating paleointensity methods: A case study using dusty olivine: Geochemistry Geophysics Geosystems, v. 14, no. 7, p. 2143-2158. 
Markert, H., and Heller, F., 1972, Determination of Palaeointensities of the Geomagnetic Field from Anhysteretic Remanent Magnetization Measurements: physica status solidi, v. 14, no. K47.

Mayergoyz, I. D., 1986, Mathematical model of hysteresis: Physical Review Letters, v. 56 , no. 15 , p. $1518-1521$.

Muxworthy, A. R., and Heslop, D., 2011, A Preisach method for estimating absolute paleofield intensity under the constraint of using only isothermal measurements: 1. Theoretical framework: Journal of Geophysical Research, v. 116.

Muxworthy, A. R., Heslop, D., Paterson, G. A., and Michalk, D., 2011, A Preisach method for estimating absolute paleofield intensity under the constraint of using only isothermal measurements: 2 . Experimental testing: Journal of Geophysical Research, v. 116.

Petronis, M. S., Delcamp, A., and van Wyk de Vries, B., 2013, Magma emplacement into the Lemptégy scoria cone (Chaîne Des Puys, France) explored with structural, anisotropy of magnetic susceptibility, and Paleomagnetic data: Bulletin of Volcanology, v. 75.

Pike, C. R., Roberts, A. P., and Verosuh, K. L., 1999, CHaracterizing interactions in fine magnetic particle systems using first order reversal curves: Journal of Applied Physics, v. 85, p. 6660-6667.

Rolph, T. C., and Shaw, J., 1985, A new method of palaeofield magnitude correction for thermally altered samples and its application to Lower Carboniferous lavas: Journal of the Royal Astronomical Society, v. 80, no. 3, p. 773-781.

Schmidt, P. W., 1993, Palaeomagnetic cleaning strategies: Physics of the Earth and Planetary Interiors, v. 76, no. 1-2, p. 169-178.

Shaw, J., 1974, A New Method of Determining the Magnitude of the Palaeomagnetic Field: Application to five historic lavas and five archaeological samples: Geophys. J. R. astr. Soc., v. 39, p. 133-141.

Tarduno, J. A., Cottrell, R. D., and Smirnov, A. V., 2006, The paleomagnetism of single silicate crystals: Recording geomagnetic field strangth during mixed polarity 
inervals, superchrons, and inner core growth: Reviews of Geophysics, v. 41, no. 1.

Tarduno, J. A., and Smirnov, A. V., 2004, The paradox of low field values and the longterm history of the geodynamo, in Channell, J. E. T., Kent, D. V., Lowrie, W., and Meert, J. G., eds., Timescales of the Paleomagnetic Field, Volume 145, AGU Geophysical Monograph Series, p. 75-84.

Tauxe, L., 2007, Paleointensities: Treatise on Geophysics, v. 5, p. 509-563.

Tauxe, L., Bertram, H. N., and Seberino, C., 2002, Physical interpretation of hysteresis loops: Micromagnetic modeling of fine particle magnetite: Geochemistry Geophysics Geosystems, v. 3, no. 10.

Tauxe, L., Mullender, T. A. T., and Pick, T., 1996, 回回Potbellies, wasp-waists, and superparamagnetism in magnetic hysteresis: Journal of Geophysical Research, v. 101, p. 571-583.

Tauxe, L., Pick, T., and Kok, Y. S., 1995, Relative paleointensity in sediments: a pseudo-Thellier approach: Geophysical Research Letters, v. 22, no. 21, p. 2885-2888.

Thellier, E., and Thellier, O., 1959, Sur L'intensite de champ magnetique terrestre dans le passe historique et geologique: Annales de Geophysique, v. 15, p. 285376.

Tsunakawa, H., and Shaw, J., 1994, The Shaw method of palaeointensity determinations and its application to recent volcanic rocks: Geophys. J. Int., v. 118, p. 781-787.

Verwey, E. J. W., 1939, Electron conduction of magnetite (Fe304) and its transition point at low temperatures: Nature, v. 144, p. 327-328.

Yamamoto, Y., and Tsunakawa, H., 2005, Geomagnetic field intensity during the last 5 Myr: LTD-DHT Shaw palaeointensities from volcanic rocks of the Society Islands, French Polynesia: Geophys. J. Int., v. 162, p. 79-114.

Yamamoto, Y., Tsunakawa, H., and Shibuya, H., 2003, Palaeointensity study of the Hawaiian 1960 lava: implications for possible causes of erroneously high intensities: Geophys. J. Int., v. 153, p. 263-276. 
Yu, Y., 2006, How accurately can NRM/SIRM determine the ancient planetary magnetic field intensity?: Earth and Planetary Science Letters, v. 250, p. 2737.

-, 2010, Paleointensity determination using anhysteretic remanence and saturation isothermal remanence: Geochemistry Geophysics Geosystems, v. 11, no. 2.

Yu, Y., Dunlop, D. J., and Özdemir, Ö., 2003, Are ARM and TRM analogs? Thellier analysis of ARM and pseudo-Thellier analysis of TRM: Earth and Planetary Science Letters, v. 205, p. 325. 